Rosenberg \& Lund,WARM332, Feb 13, 2008

\title{
Modeling Integrated Decisions for a Municipal Water System with Recourse and Uncertainties: Amman, Jordan
}

\author{
David E. Rosenberg and Jay R. Lund \\ Department of Civil \& Environmental Engineering \\ University of California, Davis \\ Email: derosenberg@ucdavis.edu \\ jrlund@ucdavis.edu
}

\begin{abstract}
Stochastic mixed-integer optimization is used to identify a portfolio of long- and short-term supply and conservation actions for a municipal water system to cost-effectively accommodate a distribution of water shortages. Alternative robust, grey-number, and best/worst case formulations systematically explore implications of uncertainties in action costs, life spans, water volumes gained or saved, shortage levels, and shortage probabilities. A detailed example for Amman, Jordan considers 23 potential actions. Results show: (i) Remarkable consistency occurs across the different modeling approaches. (ii) Conserving water-reducing leakage and targeting select customers to install water efficient appliances-plays an important and growing role over time. (iii) A delayed need for large supply projects like pumping the Disi aquifer. (iv) No role appears for seawater desalination (Red-Dead Canal) before 2040. (v) Desalinating brackish Zara-Ma'een water is the low-cost option to increase water availability to customers but requires substantial capital investments. And (vi) two shortcomings arise for grey-number and best/worst case approaches.
\end{abstract}

Keywords: stochastic mixed-integer optimization; household conservation; interval number; shortage management; Amman; Jordan.

\section{Introduction}

Uncertain surface water supplies, groundwater overdraft, rapid population growth, and sudden immigration make water shortages pressing or impending realities for Amman, Jordan and many other urban water systems. Shortages are problematic because they often cause service disruptions that promote distrust in the system service and force customers to seek expensive and risky alternative provisions. Disruptions also cost lost revenues, necessitate irregular and more expensive operations, increase the likelihood of water-borne disease outbreaks, or cause environmental degradation. Any disruption can spur public relations disasters. Planning to avoid and manage shortages is an active and 
expanding area of integrated water resources management (IWRM) (Jaber and Mohsen 2001; Joench-Clausen and Fugl 2001; Scott et al. 2003; Thomas and Durham 2003; Wilchfort and Lund 1997; Wolf and Murakami 1995).

Recent IWRM literature emphasizes planning that

1. Considers a wide range of potential long and short-term new supply and conservation actions,

2. Characterizes each action in terms of a financial cost, economic cost, and effective water quantity added or conserved,

3. Describes interactions among management actions,

4. Identifies events and likelihoods for which the system must deliver water, and

5. Uses stochastic programming to suggest a set of actions that minimize costs to provide service through all expected events.

This approach extends traditional project evaluation such as cost-benefit analysis in two ways. First, IWRM involves stakeholders in planning-especially at the beginning-to identify, describe, and characterize potential actions. Second, actions are not mutually exclusive. Many actions together may more effectively meet service objectives rather than a single, best, or "magic bullet” option. For example, a system operator can develop new water supplies, encourage or require customers to reduce their water use, reduce physical leakage from the distribution system, curtail accounting losses to increase revenues (Table 1), or combine some or all options. The operator also can initiate emergency actions (water transfers, water use restrictions, ration service, etc.) during a crisis, invest capital for new infrastructure or water use efficiency well in advance of expected shortages, or both. Selecting, combining, and timing actions while considering interactions and uncertainties are key aspects of planning decisions. Managing for 
multiple objectives such as costs, revenue generation, service provision, environmental regulations, social, and equity concerns should also factor into the planning.

Integrated planning to meet shortages is often done using stochastic optimization with recourse (staged programming). Recent applications include for a hypothetical household (Lund 1995), California’s East Bay Municipal Utility District (Jenkins and Lund 2000; Wilchfort and Lund 1997), and residential users in California (Garcia-Alcubilla and Lund 2006) and Amman, Jordan (Rosenberg et al. 2007). Elsewhere, stochastic optimization with recourse has seen extensive use in production planning, facilities location, capacity expansion, energy investment, environmental management, water management, agriculture, telecommunications, design of chemical processes, and finance (for reviews, see Sahinidis 2004; Sen and Higle 1999). The technique works as follows.

Decisions are partitioned into two types. Long-term (first- or primary-stage) decisions are taken before stochastic information is revealed. After the uncertain state is known, shortterm (secondary- or recourse-stage) decisions are then implemented to cover the outstanding shortfall not met by long-term ones. Short-term decisions apply only to the particular state. Figure 1a shows the decision tree structure. For shortage management, stochastic states are shortage events with each shortage described by a shortage level (water volume) and likelihood (probability). Together, long-term actions plus sets of short-term actions for each event constitute the decision portfolio-mix of actions - to respond to the distribution of shortages.

Stochastic programs for shortage management have been exclusively formulated as deterministic-equivalent models that use singular, point values for all numerical inputs. Numerical uncertainties in model parameters (action costs, life spans, effective volume of water added or saved, etc.) are generally investigated reactively (after solution) using sensitivity analysis (Lund 1995), Monte-Carlo simulations (Garcia-Alcubilla and Lund 2006; Rosenberg et al. 2007), or iterative simulation and optimization (Jenkins and Lund 
2000). Reactive analysis requires numerous successive model runs. Yet, many proactive stochastic programming approaches exist to systematically include numerical uncertainties in a single, unified model formulation (Sahinidis 2004; Sen and Higle 1999). Robust optimization can minimize action or cost deviations across a variety of data scenarios (Mulvey et al. 1995). Probabilistic programming satisfies chance constraints with specified reliability. Flexible programs sometimes allow constraint violations. And possibilistic programs permit specifying model coefficients over fixed or uncertain (i.e., fuzzy) intervals. Fixed intervals are also called grey numbers (Ishibuchi and Tanaka 1990) with algorithms available to decompose stochastic grey-number formulations into two interacting deterministic-equivalent sub-models whose solutions can identify stable, feasible ranges for the objective function and decision variables (Huang et al. 1995; Huang and Loucks 2000; Li et al. 2006; Maqsood and Huang 2003). Additionally, the long-standing approach of best / worst-case analysis simply solves the deterministic-equivalent program twice for the combinations of parameter values that represent the most- and least- favorable conditions.

However, in reviewing stochastic optimization with uncertainty, Sahinidis (2004, p. 979) concludes with a "need for systematic comparison between the different modeling philosophies.” Also, our review of grey-number optimization finds a focus on model formulations and solution approaches for hypothetical examples.

Here, our three-fold objective is practical, methodological, and to extend prior householdscale shortage management work in Amman, Jordan (Rosenberg 2007; Rosenberg et al. in press; Rosenberg et al. 2007) to the city scale. We 1) Identify cost effective ways for Amman water managers to bundle supply enhancement and conservation actions to cope with current and forecasted shortages, 2) Compare several existing approaches to incorporate uncertainties in the optimization, and 3) Show how targeting selected customers to install water efficient appliances and reduce their billed water use can fit with other municipal system actions potentially taken to acquire new supplies, reduce 
physical leakage, or curtail accounting losses. The paper is organized as follows. Section 2 reviews deterministic-equivalent, robust, grey-number, and best/worst case model formulations. Section 3 describes the Amman, Jordan water system, potential actions, and shortages. Section 4 presents and discusses results. And section 5 concludes.

\section{Model formulations}

This section describes four approaches to incorporate uncertainties in a stochastic program with recourse for a municipal water system. Each program identifies the water management actions that minimize a municipal water operator's expected costs to provide water service over a range of probabilistic seasonal events, has two stages (longand short-term decisions), and accommodates action interactions (demand hardening, supply softening) plus other physical limitations. These four approaches to incorporate uncertainties can then be compared.

The first approach is a deterministic-equivalent mixed integer program (single, point data inputs and decision outputs). It extends an existing deterministic-equivalent linear program (Wilchfort and Lund 1997) to include more management actions, integer decisions, interactions from additional conservation actions, and a constraint on reuse of treated wastewater. These extensions also address intermittent supply operations and probabilistic representations of the costs and water savings achieved when targeting select customers to install water efficient appliances (Rosenberg et al. 2007).

The remaining approaches attempt to systematically address uncertainties in the first model's inputs. A robust program (Mulvey et al. 1995) identifies a single set of decision outputs over varying scenarios of data input. A grey-number program (Huang and Loucks 2000) shows feasible ranges for decision outputs using fixed lower and upper bounds on data inputs. Finally, a best / worst-case analysis solves the deterministic-equivalent program twice with parameter values that represent the most- and least- favorable conditions. Figure 1 shows decision trees for the first three approaches. 


\subsection{Deterministic-equivalent formulation}

A deterministic equivalent of the stochastic program with recourse uses point estimates for all input parameters, including action costs, life spans, water volumes saved or gained, interaction functions, shortage event levels and probabilities. It extends an existing formulation (Wilchfort and Lund 1997) to an intermittent water supply system.

\subsubsection{Decision Variables}

Decision variables are levels of implementation for long- and short-term new supply and conservation actions. We denote $L_{i}$ the implementation level of long-term action $i$ (binary or integer) and $S_{j, s, e}$ the water supply volume added or conserved by short-term action $j$ during season $s$ and probabilistic shortage event $e$ ( $\mathrm{m}^{3} /$ season).

\subsubsection{Model Formulation}

A risk-neutral water system manager will operate for an expected value decision criteria and try to minimize the probability-weighted sum of short- and long-term water management action costs subject to requirements to meet shortages during each shortage event, upper limits on long- and short-term actions, limits on water conveyed through the distribution system, and capacity for waste-water treatment and reuse. The deterministicequivalent objective function minimizes expected annual costs, $Z_{1}$ [\$ year ${ }^{-1}$ ],

$$
\text { Minimize } Z_{1}=\sum_{i=1}^{I} c_{1, i}\left(L_{i}\right)+\sum_{s=1}^{S} \sum_{e=1}^{E} p_{e} \sum_{j=1}^{J} c_{2, j, s}\left(S_{j, s, e}\right)
$$

Objective function costs include annualized costs, $c_{1, i}\left[\$\right.$ year $\left.{ }^{-1}\right]$ for long-term actions $\left(L_{i}\right)$ plus event costs, $c_{2, j, s}\left[\$ \mathrm{~m}^{-3}\right.$ event $\left.^{-1}\right]$, for short-term actions $\left(S_{j, s, e}\right)$ weighted by event probabilities, $p_{e}$ [fraction].

Equation (1a) is subject to the following constraints:

- Water savings and increased supplies must meet or exceed the expected shortage level, $d_{s, e}$ [volume], for each season $s$ of each event $e$, 


$$
\sum_{i=1}^{I} s f_{i, s, e} L_{i}+\sum_{j=1}^{J}\left(1-a l_{j}\right) \cdot S_{j, s, e} \geq d_{s, e}, \forall s, e .
$$

Here, a savings factor, $s f_{i, s, e}\left[\mathrm{~m}^{3}\right.$ event $\left.^{-1}\right]$, describes water savings effectiveness for long-term conservation action $i$ in season $s$ and event $e$. The accounting loss indicator, $a l_{j}$ [fraction], takes the value of 1 when short-term action $j$ contributes a financial accounting of water rather than actual water savings (such as retrofitting under-reporting meters or installing meters on illegal connections).

- Upper limits, $l_{\max i}$ [integer], on long-term actions

$$
L_{i} \leq l_{\max i}, \forall i
$$

- Upper limits, $s_{\max j, s, e}\left[\mathrm{~m}^{3}\right.$ event $\left.^{-1}\right]$, on short-term actions given interactions, $g_{i, j}$ [fraction], with other long-term actions,

$$
S_{j, s, e} \leq s_{\max j, s, e}+\sum_{i=1}^{I} g_{i, j} s f_{i, s, e} L_{i}, \forall j, s, e
$$

A positive interaction $\left(g_{i, j}>0\right)$ increases the effectiveness of short-term action $j$ when long-term action $i$ is implemented (supply enhancement). Conversely for negative $g$ (demand hardening). Use of some short-term actions requires first putting in place a long-term action. For example, delivering water with a systemowned tanker truck requires purchasing the truck; operating new groundwater, surface water, and desalination facilities require building the capacity. These interactions are represented by $g=+1$. Other short-term actions, such as detecting and repairing network leaks, restricting outdoor water use, or rationing become less effective after restructuring the distribution system or when customers install water efficient appliances or landscaping. These interactions are represented by $g$ $<0$. Finally, $g$ is zero for short-term actions such as buying agricultural water, enhancing precipitation, renting tanker trucks, or disconnecting illegal users that have a fixed upper limit and do not interact with long-term actions. 
- Mass balance on system treatment and distribution capacity. The existing system capacity in season $s$ and event $e, C A P_{s, e}\left[\mathrm{~m}^{3}\right.$ event $\left.^{-1}\right]$, plus expansions by new treatment plants or primary pipelines must exceed the water supplied from the subset $m$ of short-term actions that feed water into the conveyance system,

$$
\sum_{m=1}^{M} S_{m, s, e} \leq C A P_{s, e}+s f_{i, s, e} L_{i}, \forall s, e, \text { and } i=\text { expand capacity. }
$$

Here, we consider one expansion step, $s f_{\text {expand capacity,s,e }}\left[\mathrm{m}^{3}\right.$ event $\left.^{-1}\right]$. However, when economies of scale exist, expansion increments must be integer variables with additional constraints to enforce the correct ordering of implementation with declining costs.

- Mass balance on reuse of treated wastewater. Reuse is also limited by return flows from supplied water, treatment efficiency, and conveyance losses. Here, a treated wastewater availability factor, $t_{s}$ [fraction], applies to the subset $k$ of short-term supply enhancement actions in season $s$ generating wastewater,

$$
S_{j, s, e} \leq t_{s} \cdot \sum_{k=1}^{K} S_{k, s, e}, \forall s, e \text {, and } j=\text { reuse treated wastewater, and }
$$

- Non-negativity of decision variables,

$$
L_{i} \geq 0, \forall i ; \quad S_{j, e, s} \geq 0, \forall j, s, e .
$$

\subsubsection{Model Discussion and Solution}

The event probabilities and expected shortage levels ( $p_{e}$ and $d_{s, e}$ ) constitute a set of stochastic conditions for which the system must operate. Their values are discrete shortage levels that range from small to more severe, characterize the probability distribution of shortages, and influence the extent to which long- and short-term actions are needed. Implementing a portfolio of fixed long- and event-specific short-term supply and conservation actions allows for flexibility. Long-term actions generate new supplies 
or water savings during all events; short-term actions are implemented only in the events as needed. And, as shortages become severe, more (higher-cost) short-term actions are implemented.

The program can be expressed and solved as a mixed-integer linear program when the cost functions ( $c_{1}$ and $c_{2}$ ) can be expressed as unit costs (or are concave and made piecewise linear) and the other model inputs $\left(p_{e}, s f_{i, e, s}, d_{s, e}, l_{\max i}, s_{\max j, s, e}, g_{i, j}\right.$, and $\left.t_{s}\right)$ are represented by point values.

\subsection{Robust formulation}

At times, model inputs (i.e., $c_{1}, c_{2}, p_{e}, s f_{i, s}, d_{s, e}, l_{\max i}, s_{\max j, s, e}, g_{i, j}$, and $t_{s}$ ) are not known definitively. Also, it is desirable to find a single good solution over a range of situations or input values. This type of goal programming seeks a robust solution that is nearly optimal for all scenarios of input data (Mulvey et al. 1995). Typically, robust optimization penalizes the objective function for small violations of constraint(s) in one or more data scenarios. The robust formulation can also minimize cost deviations across data scenarios. Here, we focus on expected costs, exclude a penalty, but instead set the upper limit for one management action sufficiently large so that it can be implemented (when needed) to satisfy all constraints. This “action of last resort” (Tier 2 rationing here) is the most expensive action and its cost is alternatively interpreted as a penalty.

The robust optimization program is formulated from the deterministic-equivalent model (1) as follows: First, specify scenario-specific model constraints (Eq. 1b through 1h) and short-term decisions $\left(S_{j, s, e, d}\right)$ for each data scenario $d(1,2, \ldots, D)$. And second, weight the expected annual cost for the data scenario by the scenario likelihood, $p d_{d}$ [fraction]. Parameter values for each data scenario can be specified a priori by the modeler, or, if individual and joint probability distributions are known for them, sampled prior to optimization. The robust optimization program is: 


\subsubsection{Decision variables}

Primary stage decisions [long-term actions, $L_{i}$ (integer)] do not change, but secondary stage decisions [short-term actions, $S_{j, s, e, d}\left(\mathrm{~m}^{3} /\right.$ season)] expand to consider the water volume in each season $s$, event $e$, and data scenario $d$.

\subsubsection{Model formulation}

The risk-neutral water system manager will minimize its expected long- and short-term water management costs over all seasons, events, and data scenarios. The robust objective function, $Z_{2}\left[\$\right.$ year $\left.^{-1}\right]$, is:

$$
\text { Minimize } Z_{2}=\sum_{d=1}^{D} p d_{d} \cdot\left[\sum_{i=1}^{I} c_{1, i, d}\left(L_{i}\right)+\sum_{s=1}^{S} \sum_{e=1}^{E} p_{e, d} \sum_{j=1}^{J} c_{2, j, s, d}\left(S_{j, s, e, d}\right)\right] \text {. }
$$

Subject to:

$$
\begin{aligned}
& \sum_{i=1}^{I} s f_{i, s, e, d} L_{i}+\sum_{j=1}^{J}\left(1-a l_{j}\right) \cdot S_{j, s, e, d} \geq d_{s, e, d}, \forall s, e, d, \\
& L_{i} \leq l_{\max i, d}, \forall i, d, \\
& S_{j, s, e, d} \leq s_{\max j, s, e, d}+\sum_{i=1}^{I} g_{i, j, d} s f_{i, s, e, d} L_{i}, \forall j, s, e, d, \\
& \sum_{m=1}^{M} S_{m, s, e, d} \leq C A P_{s, e}+s f_{i, s, e, d} L_{i}, \forall s, e, d, \text { where } i=\text { expand capacity, } \\
& S_{j, s, e, d} \leq t_{s, d} \cdot \sum_{k=1}^{K} S_{k, s, e, d}, \forall s, e, d, \text { where } j=\text { reuse treated wastewater, and } \\
& L_{i} \geq 0, \forall i ; \quad S_{j, e, s, d} \geq 0, \forall j, s, e, d .
\end{aligned}
$$

Here, parameters $c_{1, d}, c_{2, j, s, d}, p_{e, d}, s f_{i, s, e, d}, d_{s, e, d}, l_{\max i, d}, s_{\max j, s, e, d}, g_{i, j, d}$, and $t_{s, d}$ have the same meaning as in model (1) but take different values for each scenario $d$. Similarly, constraints to meet each shortage level (Eq. 2b), upper limits for long- and short-term actions (Eqs. 2c and 2d), distribution system capacity (Eq. 2e), reuse of treated wastewater (Eq. 2f), and non-negativity for short-term actions (Eq. 2h) expand to cover each scenario $d$. 
Rosenberg \& Lund,WARM332, Feb 13, 2008

\subsubsection{Model discussion and solution}

The robust model is similar to the deterministic-equivalent model except that it optimizes over a set of equally weighted data scenarios that represent different parameter values. The modeler chooses the number of data scenarios, $D$ (integer), to balance uncertainty enumeration and available computing resources. Larger $D$ generates more short-term decision variables, constraints, and solution effort. However, each input for each data scenario is a point value; robust model (2) is solved as a mixed integer program.

The robust solution will consist of a single set of long-term actions, $L_{i}$ (integer), and sets

of short-term actions, $S_{j, e, s, d}\left(\mathrm{~m}^{3} /\right.$ season), for each season, event, and data scenario. Often, it may help to summarize the numerous outputs by the number of data scenarios where a short-term-action is implemented, the average, or distribution of implementation levels or costs. Data presentation should depend on informational needs.

\subsection{Grey-number formulation}

The grey-number formulation incorporates numerical uncertainties when parameter values are expressed as intervals; its solution identifies feasible, stable ranges for the objective function and decision variables. These ranges are then used to select decision alternatives and contrast with point solution values identified by the deterministicequivalent and robust approaches.

Grey numbers take values between fixed lower and upper bounds but with unknown distributions (i.e., $W^{ \pm} \in\left[W^{-}, W^{+}\right]$or $W^{-} \leq W^{ \pm} \leq W^{+}$, also called interval numbers) and have well described mathematical properties and use in optimization (Huang et al. 1994; Huang et al. 1995; Ishibuchi and Tanaka 1990), including stochastic linear optimization programs with recourse (Huang and Loucks 2000; Maqsood and Huang 2003). Below, we follow Haung and Loucks' model formulation and solution algorithm. 


\subsubsection{Model formulation and solution algorithm}

First, we substitute a grey number for each uncertain parameter $\left(c_{1}^{ \pm}, c_{2, j, s}{ }^{ \pm}, s f_{i, s, e}{ }^{ \pm}, d_{s, e}{ }^{ \pm}\right.$, $s_{\text {max jj,s, }}^{ \pm}, g_{i, j}^{ \pm}$, and $\left.t_{s}^{ \pm}\right)$. These substitutions turn the objective function $\left(Z_{3}^{ \pm}\right)$and all decision variables $\left(L_{i}^{ \pm}\right.$and $\left.S_{j, s, e}{ }^{ \pm}\right)$grey and yield a grey optimization model (3).

$$
\text { Minimize } Z_{3}^{ \pm}=\sum_{i=1}^{I} c_{1, i}^{ \pm}\left(L_{i}^{ \pm}\right)+\sum_{s=1}^{S} \sum_{e=1}^{E} p_{e} \sum_{j=1}^{J} c_{2, j, s}^{ \pm}\left(S_{j, s, e}^{ \pm}\right)
$$

Subject to

$$
\begin{aligned}
& \sum_{i=1}^{I} s f_{i, s, e}^{ \pm} L_{i}^{ \pm}+\sum_{j=1}^{J}\left(1-a l_{j}\right) \cdot S_{j, s, e}^{ \pm} \geq d_{s, e}^{ \pm}, \forall s, e . \\
& L_{i}^{ \pm} \leq l_{\max i}, \forall i . \\
& S_{j, s, e}^{ \pm} \leq s_{\max j, s, e}^{ \pm}+\sum_{i=1}^{I} g_{i, j}^{ \pm} s f_{i, s, e}^{ \pm} L_{i}^{ \pm}, \forall j, s, e . \\
& \sum_{m=1}^{M} S_{m, s, e}^{ \pm} \leq C A P_{s, e}+s f_{i, s, e}^{ \pm} L_{i}^{ \pm}, \forall s, e, \text { where } i=\text { expand capacity, } \\
& S_{j, s, e}^{ \pm} \leq t_{s}^{ \pm} \cdot \sum_{k=1}^{K} S_{k, s, e}^{ \pm}, \forall s, e, \text { where } j=\text { reuse treated wastewater, and } \\
& L_{i}^{ \pm} \geq 0, \forall i ; \quad S_{j, s, e}^{ \pm} \geq 0, \forall j, s, e .
\end{aligned}
$$

Here, $Z_{3}^{ \pm}$(\$/year) is the uncertain grey objective function with lower- and upper bounds, respectively, $\mathrm{Z}_{3}{ }^{-}$and $\mathrm{Z}_{3}{ }^{+}$; similarly for the other decision variables and parameters.

We solve grey optimization model (3) by decomposing it into two deterministic submodels. The two sub-models correspond to the lower and upper bounds of the grey objective-function and interact. With cost-minimization, uncertain long-term decisions $\left(L_{i}^{ \pm}\right)$are identified by first solving the lower-bound sub-model. Then, the determined long-term action levels $\left(L_{i}^{*}\right)$ are used to solve the upper-bound sub-model for upper limits on short-term actions $\left(S_{j, s, e}{ }^{+}\right)$. Decomposition and solution requires three steps.

Step 1. Set up and solve the sub-model to identify the objective function lower bound, $Z_{3} \cdot$. Use parameter values that lower expenditures on and the need for long- and short- 
term actions $\left(L_{i}^{ \pm}\right.$and $\left.S_{\text {j.s.e }}{ }^{-}\right)$[i.e., small capital and operational costs $\left(c_{1}{ }^{-}\right.$and $\left.c_{2}{ }^{-}\right)$, large water savings when adopting long-term conservation actions $\left(s f^{+}\right)$, small shortage levels $\left(d^{-}\right)$, large upper limits for short-term actions $\left(s_{\max }{ }^{+}\right)$, interactions that increase upper limits of short term actions $\left(g^{+}\right)$, and large treated wastewater availability for reuse $\left.\left(t^{+}\right)\right]$. The program solves for long-term decision levels $\left(L_{i}^{ \pm}\right)$since these values influence the objective function positively or negatively depending on recourse (short-term) decisions. The lower-bound sub-model is:

Minimize $Z_{3}^{-}=\sum_{i=1}^{I} c_{1, i}^{-}\left(L_{i}^{ \pm}\right)+\sum_{s=1}^{S} \sum_{e=1}^{E} p_{e} \sum_{j=1}^{J} c_{2, j, s}^{-}\left(S_{j, s, e}^{-}\right)$

Subject to

$$
\begin{aligned}
& \sum_{i=1}^{I} s f_{i, s, e}^{+} L_{i}^{ \pm}+\sum_{j=1}^{J}\left(1-a l_{j}\right) \cdot S_{j, s, e}^{-} \geq d_{s, e}^{-}, \forall s, e . \\
& L_{i}^{ \pm} \leq l_{\max i}, \forall i . \\
& S_{j, s, e}^{-} \leq s_{\max j, s, e}^{+}+\sum_{i=1}^{I} g_{i, j}^{+} s f_{i, s, e}^{+} L_{i}^{ \pm}, \forall j, s, e . \\
& \sum_{m=1}^{M} S_{m, s, e}^{-} \leq C A P_{s, e}+s f_{i, s, e}^{+} L_{i}^{ \pm}, \forall s, e, \text { where } i=\text { expand capacity, } \\
& S_{j, s, e}^{-} \leq t_{s}^{+} \cdot \sum_{k=1}^{K} S_{k, s, e}^{-}, \forall s, e, \text { where } j=\text { reuse treated wastewater, and } \\
& L_{i}^{ \pm} \geq 0, \forall i ; \quad S_{j, s, e}^{-} \geq 0, \forall j, s, e .
\end{aligned}
$$

Lower-bound sub-model (4) has point numerical inputs and is solved as a deterministic mixed integer program. The solution identifies optimal long-term actions $\left(L_{i}^{*}\right)$ and short-term action levels $\left(S_{\text {j.s.e }}{ }^{-}\right)$that minimize cost under favorable economic conditions. Long-term levels become inputs to the upper-bound sub-model.

Step 2. Set up and solve the upper bound sub-model to identify $Z_{3}^{+}$. Use objective function coefficients and constraint values that require large expenditures and increase the need for short-term actions $\left(S_{\text {j.s.e }}{ }^{+}\right)$[i.e., large capital and operational costs $\left(c_{1}^{+}\right.$and $\left.c_{2}{ }^{+}\right)$, small water savings when adopting long-term conservation 
actions ( $s f)$, large shortage levels $\left(d^{+}\right)$, small upper limits for short-term actions $\left(s_{\max }{ }^{-}\right.$ ), interactions that decrease upper limits of short term actions $\left(g^{-}\right)$, and small treated wastewater availability for reuse $\left(t^{-}\right)$]. The upper-bound sub-model excludes constraints (c) and (g) as long-term decisions $\left(L_{i}{ }^{*}\right)$ were previously fixed. The sole decisions are short-term action levels $\left(S_{j, s, e}{ }^{+}\right)$that minimize expenditures with unfavorable economic conditions. The upper-bound sub-model is:

Minimize $Z_{3}^{+}=\sum_{i=1}^{I} c_{1, i}^{+}\left(L_{i}^{*}\right)+\sum_{s=1}^{S} \sum_{e=1}^{E} p_{e} \sum_{j=1}^{J} c_{2, j, s}^{+}\left(S_{j, s, e}^{+}\right)$

Subject to

$$
\begin{aligned}
& \sum_{i=1}^{I} s f_{i, s, e}^{-} L_{i}^{*}+\sum_{j=1}^{J}\left(1-a l_{j}\right) \cdot S_{j, s, e}^{+} \geq d_{s, e}^{+}, \forall s, e . \\
& S_{j, s, e}^{+} \leq s_{\max j, s, e}^{-}+\sum_{i=1}^{I} g_{i, j}^{-} s f_{i, s, e}^{-} L_{i}^{*}, \forall j, s, e . \\
& \sum_{m=1}^{M} S_{m, s, e}^{+} \leq C A P_{s, e}+s f_{i, s, e}^{-} L_{i}^{*}, \forall s, e, \text { where } i=\text { expand capacity, } \\
& S_{j, s, e}^{+} \leq t_{s}^{-} \cdot \sum_{k=1}^{K} S_{k, s, e}^{+}, \forall s, e, \text { where } j=\text { reuse treated wastewater, and } \\
& S_{j, s, e}^{+} \geq S_{j, s, e}^{-}, \forall j, s, e .
\end{aligned}
$$

Upper-bound sub-model (5) also has point numerical inputs and is solved as before.

Step 3. Solutions to sub-models (4) and (5) span stable, feasible ranges for the objective function and decision variables. These ranges are $Z_{3}{ }^{ \pm}$opt $=\left[Z_{3}^{-}, Z_{3}{ }^{+}\right], L_{i}{ }^{*}$, and $S_{j, s, e \text { opt }}^{ \pm}=\left[S_{j, s, e}^{-}, S_{j, s, e}^{+}\right]$where $Z_{3}^{-}, L_{i}{ }^{*}$, and $S_{j, s, e}^{-}$are solutions to lower-bound submodel (4) and $\mathrm{Z}_{3}{ }^{+}$and $S_{j, s, e}^{+}$are solutions to upper-bound sub-model (5).

\subsubsection{Discussion}

Grey number optimization incorporates parameter intervals directly in the model formulation. Decomposing and solving the two interacting deterministic sub-models requires minimal computational effort and identifies stable, feasible ranges for the 
objective function and short-term decisions. Decision makers can then select short-term action levels within the feasible ranges to develop policy alternatives.

\subsection{Best / worst-case formulation}

Best / worst-case analysis has a long history of use in optimization to help judge a system's capability to realize a desired goal. It solves a deterministic-equivalent program twice for the combinations of parameter values that represent the most- (best) and least(worst) favorable conditions and identifies contrasting approaches to operate the system under different circumstances. The best / worst-case formulation nearly resembles the grey-number approach minus interaction among the sub-models. In a cost minimization application, the best case is identical to the lower-bound grey-number sub-model (4). The worst case modifies the upper-bound sub-model (5) to (i) allow separate long-term decisions for the worst case $\left(L_{i}^{+}\right)$and (ii) relax lower-limits on short-term decisions.

$$
\text { Minimize } Z_{3}^{+}=\sum_{i=1}^{I} c_{1, i}^{+}\left(L_{i}^{+}\right)+\sum_{s=1}^{S} \sum_{e=1}^{E} p_{e} \sum_{j=1}^{J} c_{2, j, s}^{+}\left(S_{j, s, e}^{+}\right)
$$

Subject to

$$
\begin{aligned}
& \sum_{i=1}^{I} s f_{i, s, e}^{-} L_{i}^{+}+\sum_{j=1}^{J}\left(1-a l_{j}\right) \cdot S_{j, s, e}^{+} \geq d_{s, e}^{+}, \forall s, e . \\
& L_{i}^{+} \leq l_{\max i}, \forall i . \\
& S_{j, s, e}^{+} \leq s_{\max j, s, e}^{-}+\sum_{i=1}^{I} g_{i, j}^{-} s f_{i, s, e}^{-} L_{i}^{+}, \forall j, s, e . \\
& \sum_{m=1}^{M} S_{m, s, e}^{+} \leq C A P_{s, e}+s f_{i, s, e}^{-} L_{i}^{+}, \forall s, e, \text { where } i=\text { expand capacity, } \\
& S_{j, s, e}^{+} \leq t_{s}^{-} \cdot \sum_{k=1}^{K} S_{k, s, e}^{+}, \forall s, e, \text { where } j=\text { reuse treated wastewater, and } \\
& L_{i}^{+} \geq 0, \forall i ; S_{j, s, e}^{+} \geq 0, \forall j, s, e .
\end{aligned}
$$

Here, $L_{i}^{+}$[integer $]$and $S_{j, s, e}{ }^{+}\left[\mathrm{m}^{3}\right.$ event $\left.{ }^{-1}\right]$ represent long- and short-term decision variable values for the worst case. Best and worst-case sub-models (4) and (6) have point numerical inputs and are solved as separate deterministic mixed integer programs. 
Rosenberg \& Lund,WARM332, Feb 13, 2008

\subsection{Model Limitations}

Limitations of stochastic linear optimization for shortage management are well described (Garcia-Alcubilla and Lund 2006; Lund 1995; Rosenberg et al. 2007; Wilchfort and Lund 1997). These limitations and potential workarounds are:

1. Expected value decisions. In the objective function, weighting short-term action costs by event probabilities gives an expected-value, risk-neutral decision criteria. However, decision makers are generally risk-adverse and seek to minimize the large consequences often associated with extreme but unlikely events. Risk aversion can be accommodated in two ways: 1) revise upward probabilities for extreme shortage events (above their hydrologic likelihood), or 2) modify the robust objective function to minimize cost variance across data scenarios, for example, Minimize $Z_{2}{ }^{\prime}=\sum_{d=1}^{D}\left(Z_{d}-\frac{1}{D} \sum_{d=1}^{D} Z_{d}\right)^{2}$.

2. Drought triggers. Stochastic programming is a planning tool to respond to shortages of long duration and recurrent frequency. However, for systems that face occasional shortages of a few days or weeks duration (such as in the eastern United States), trigger rules may play a more critical role in optimizing shortage responses. Yet, once an event is triggered or identified, a simplified version of the stochastic program resembling upper bound sub-model (5) can identify the optimal mix of short-term actions to respond to the shortage event.

3. Event independence. The approach assumes shortage events occur independently of one-another ignoring effects of event timing or sequence. This assumption precludes actions such as groundwater banking or reservoir storage that allow temporal water transfers (i.e., from wet to dry periods). Jenkins and Lund (2000) work around this limitation by simulating different reservoir storage or re- 
operation policies, calculating the resulting shortage probability distributions, and then optimizing for each simulation run.

4. Cost minimization rather than benefit maximization. Shortage management minimizes costs subject to meeting specified shortage levels. Benefit maximization would allow answering the related and important economic question: how much water to allocate in a shortage? Or, to what extent should operators ration (restrict) supplies to cope with shortages? But benefits (particularly the utility water users derive from increased availability) are elusive to specify. Specification is further complicated when users value different levels of reliability, face complex price structures for municipal water, and have already adopted alternative long- and short-term strategies to cope with existing rationing. Yet, benefit maximization reduces to cost minimization when benefits are constant or linear with respect to the volume of water use.

\section{Example Application for Amman, Jordan}

We now apply the different stochastic optimization approaches to the Amman, Jordan water system. First, we summarize current system operations, introduce the shortage problem, describe potential management actions, and develop events for which the system must deliver water. Then we present and discuss results.

\subsection{System operation and problem identification}

Currently, the Amman system delivers about $133 \mathrm{Mm}^{3}$ per year of groundwater and imported surface water to 2.2 million persons through 360,000 residential and 40,000 non-residential connections. Figure 2 shows a schematic of existing and proposed supply and wastewater works. Water is generally available through the pipe network to customers for between 24 and 72 hours per week. 
However, nearly $45 \%$ of deliveries is non-revenue water from real and apparent losses such as physical leaks, meter reader errors, unauthorized use (theft), or meter underregistration (Figure 3). Moreover, the system overdrafts local groundwater to meet existing demands, expects increased demands fueled by $2.8 \%$ annual population growth, has limited ability to tap new local supplies, faces high costs to acquire and import water from distant sources, and periodically endures droughts that diminish the availability of existing surface water supplies. Jordan has also seen several sudden and large immigration waves that coincide with regional crisis (Hussein 2000). Approximately 2 million transients passed through Jordan during the 1990-1991 Gulf War of which 400,000 became permanent residents. Many more followed the 2003 U.S. invasion of Iraq, and still others arrived in July 2006 with the Israel and Hizbollah war. New arrivals increase demand on an already stretched water supply system.

Jordan was the focus of a major regional optimization effort (Fisher et al. 2005) and has seen several efforts to reduce residential and commercial water use (Abu-Taleb and Murad 1999; Faruqui and Al-Jayyousi 2002; IdRC 2004; Rosenberg 2007; Rosenberg et al. 2007; WEPIA 2000). But no work has systematically compared customer conservation actions with new supply or loss reduction alternatives.

An integrated modeling effort at the municipal scale can help identify a cost-effective mix of new supplies and conservation actions to bridge the expected demand-supply gap. Such analysis could also confirm and justify actions the Ministry of Water and Irrigation (MWI) and Suez Lyonnaise des Eaux/Arabtech Jardaneh and Montgomery Watson (LEMA, the management contractor for the Amman system) are planning and implementing to address existing and expected shortages.

\subsection{Potential Actions}

Tables 2 and 3 summarize 16 long-term and 7 short-term actions Amman water system managers can take to develop new supplies or reduce system use (including decreasing 
billed use, real losses, or apparent losses). We classify actions as either long- or shortterm. Long-term actions require a one-time (and generally large) capital investment and establish infrastructure for supply or conservation. These actions must be taken well in advance of any actual water delivery or use reduction. Short-term actions can be implemented when needed. They can flexibly respond to crisis or events as they occur and do not require advance planning unless conditioned on long-term infrastructure.

Information is summarized from handwritten notes, electronic files, and paper documents taken or shared during meetings, interviews, and follow-up visits in Amman between November, 2005 and January, 2006 with more than 20 managers who work for MWI, Jordan Valley Authority (JVA), Water Authority of Jordan (WAJ), LEMA, U.S. Agency for International Development (USAID), and private consultants. In general, meetings focused on the particular action within a manager's expertise. Several times, managers identified additional actions and person(s) with whom to discuss them. Ranges listed in Tables 2 and 3 for costs, life spans, and water quantities gained or saved represent reported lower and upper bounds for existing or planned projects or plants.

For several conservation actions (customer education and awareness program, rebates to customers to adopt conservation technologies, re-price water, and restrict outdoor water use), costs and quantities are aggregate results from a detailed integrated study of residential water use in Amman (Rosenberg et al. 2007). This study linked Monte-Carlo simulations of household water management choices to stochastic optimization and calibrated against the existing distribution of billed residential water use. Thus, ranges represent the $10^{\text {th }}$ and $90^{\text {th }}$ percentiles of estimated effectiveness and cost distributions for Amman households. Below, we review potential actions to cope with shortages. 
Rosenberg \& Lund,WARM332, Feb 13, 2008

\subsubsection{Supply enhancement}

$\underline{\text { Long term supply enhancement }}$

Long-term actions establish water supply infrastructure, access to sources, or develop yields.

New surface water. Dams exist on nearly all of Jordan’s natural streams. Here, capital costs and quantities represent small impoundments across desert wadis to recharge groundwater. The volume stored is available later by extraction through existing wells.

New local groundwater. Amman area groundwater is severely over-drafted. It is infeasible to pump additional large quantities of groundwater. Instead, reported ranges represent costs and quantities to drill, pump, and biologically treat a new well with production capacity from 10 and $50 \mathrm{~m}^{3}$ per hour. We allow development of 5 new wells.

New distant groundwater. MWI has recently tendered proposals to pump the Disi fossil aquifer along the southern border with Saudi Arabia and convey the water more than 200 km north to Amman (El-Nasser 2005; Nuaimat and Ghazal 2006; Taha and Magiera 2003). However, this mega-project has also previously seen financial backers withdraw and criticism about the impacts on aquifer safe yield from pumping by overlying landowners - both Jordanian and Saudi. One incidental project benefit not considered here is ability to simultaneously deliver water to and alleviate scarcities in the cities of Ma’an, Karak, and Madaba along the conveyance route to Amman.

Desalinate seawater. A second mega project envisions conveying Red Sea water more than $300 \mathrm{~km}$ north from Aqaba to the Dead Sea. The 400-meter elevation drop between the two seas can generate hydropower to desalinate the seawater (El-Nasser 2005; Nuaimat and Ghazal 2006; Taha and Magiera 2003). Desalinated seawater (potable freshwater) would then be pumped uphill to Amman. Costs reflect current estimates to 
deliver potable water to Amman. These estimates exclude environmental benefits to use desalination brine waste to restore the declining Dead Sea level.

Desalinate local brackish water. A third mega project will collect brackish waters from the Mujib, Zara, and Ma'een rivers, desalinate it by reverse osmosis, and convey treated water uphill to Amman (Nuaimat and Ghazal 2006; Taha and Magiera 2003). The ZaraMa'een project is scheduled to begin deliveries in late Summer 2006. Costs reflect recent estimates to treat and deliver potable water to Amman.

Desalinate distant brackish water. Since 2000, MWI has built more than 10 brackish water desalination plants throughout Jordan with treatment capacities ranging from 4 to $2,500 \mathrm{~m}^{3}$ per hour. These plants convert brackish water with TDS up to 10,000 ppm into potable water by reverse osmosis (WAJ, 2005). More brackish water is available and additional plants can be built (Mohsen and Al-Jayousi 1999). Capacities and costs are for an individual plant and ranges reflect low and high values seen for existing plants. Operation costs include conveyance to Amman.

Mobile desalination units. MWI recently purchased and currently operates 3 mobile desalination units. Units sit on flatbed trucks and can treat brackish water with TDS up to 4,000 ppm by reverse osmosis. MWI could purchase additional units. Operational costs include conveyance to Amman.

Tanker trucks. LEMA currently owns 19 tanker trucks with individual capacities from 6 to $12 \mathrm{~m}^{3}$. The trucks operate from 4 groundwater filling stations around Amman and deliver water to the storage tanks of customers who lack service through the pipe network or have exhausted storage between rationing periods. LEMA can purchase additional tanker trucks to expand capacity to flexibly deliver water to customers. The range of water quantities reflects annual deliveries recorded between 1999 and 2005. Operational 
costs reflect gas, personnel, maintenance, telephone, and administrative costs logged by LEMA in 2005.

Expand treatment and conveyance capacity. Imported surface water is treated the Zai treatment plant and pumped uphill to Amman. Currently, the plant operates at its capacity of $123,000 \mathrm{~m}^{3}$ per day and operations cost JD $0.16 / \mathrm{m}^{3}$ (Fisher et al. 2005, Chp. 7). The plant and pumping capacity will need expansion to import additional surface water from the Jordan Valley. Data values are from a proposal to double Zai’s capacity.

Expand wastewater treatment and reuse. Expanding wastewater treatment capacity and exchanging treated wastewater for fresh surface water used by Jordan Valley farmers can increase the freshwater available to Amman. Currently, some 56\% to 78\% of Amman customers have sewerage and generate about 71 to $79 \mathrm{Mm}^{3}$ wastewater per year. Raw influent is reduced to between 50 and $51 \mathrm{Mm}^{3}$ per year of secondary treated wastewater at 4 plants in and around Amman (despite plant capacities totaling only $33 \mathrm{Mm}^{3}$ per year). Treated wastewater is released back into Jordan River tributaries and used by downstream farmers. Ranges for water quantities and costs represent an Al-Samra plant expansion, new treatment plants for Wadi Zarka and South Amman, and include wastewater treatment and conveyance losses.

\section{$\underline{\text { Short-term supply enhancement }}$}

Short-term supply actions have an immediate and therefore flexible effect on system supply. They can be implemented when needed, in response to particular events.

Buy agricultural water. The JVA has a long-standing program to rent agricultural land from Jordan Valley farmers during drought years. The JVA solicits participants in January or February of a year. Participants take payment of between JD 800 and 1,200 per farm unit ( 1 farm unit $=40,000 \mathrm{~m}^{2}$ ) and forgo delivery of their water allocation. Water is instead conveyed to Amman for urban use. The program operated in 1990, 2001, 
and 2002 and involved 320 farm units (about 6.4 $\mathrm{Mm}^{3}$ per year). Participants either fallow their land or substitute saline shallow groundwater or polluted Jordan River water. Operational costs include payments, treatment, and conveyance to Amman.

Enhance precipitation. Pilot studies in north Jordan in the early 1990s showed that seeding clouds with silver iodide or dry ice to enhance ice particle nucleation and rainfall had the potential to increase existing winter surface runoff by 12\% (Taha and Magiera 2003). Operation costs were estimated for airplane sorties, computers, equipment, and materials, and also include conveyance to Amman.

Rent tanker trucks. Many companies, institutions, and individual owners operate tanker trucks from private wells. LEMA can rent trucks for about JD 500 per month to flexibly expand capacity to deliver water to customers. The upper limit on deliveries is the same as for LEMA-owned trucks.

\subsubsection{Conservation}

Conservation actions can reduce physical losses, billed water use, or apparent losses. Reducing billed water use also reduces revenues whereas reducing apparent losses increases revenues but does not change the existing level of water use.

\section{$\underline{\text { Long-term conservation }}$}

Long-term conservation actions must be taken well in advance of reductions seen in water use. These actions generally involve modifying the distribution system, water meters, or customer water use appliances.

Reduce physical losses. MWI has completed about 67\% of a 5-year Capital Improvement Project to restructure the Amman water distribution system to reduce physical water loss. Improvements include dividing the network into separate pressure zones, installing bulk meters, primary tanks, and gravity fed distribution for each zone, optimizing flows, and 
reducing system pressure. Tests show between $18 \%$ and $35 \%$ reduction in water loss that amounts to water savings between 24 and $46 \mathrm{Mm}^{3}$ per year.

Targeted water conservation program. Detailed modeling of Amman residential water customer behaviors showed that targeting specific customers to install water efficient appliances can reduce aggregate residential water use nearly 33\% (Rosenberg et al. 2007). Several customers can benefit financially by installing toilet dual flush mechanisms, low-flow showerheads, faucet aerators, drip irrigation, water efficient laundry machines and landscapes, etc. The crux is to identify customers with potential to save water and money, determine which specific action(s) those customers should adopt, and find engaging ways to promote and motivate adoption. Here, we estimate capital costs for education, awareness, and administration but exclude retrofit costs based on the USAID budget for a prior Jordan water conservation program. Customers pay to install water efficient appliances and reduce their piped water charges. These avoided costs represent lost revenues or operational costs to the water system operator.

Rebate programs. The detailed Amman study simultaneously identified the subsidies a further subset of residential customers might require to install water efficient appliances (Rosenberg et al. 2007). Toilet dual flush mechanisms, kitchen faucet aerators, and drip irrigation showed large water savings for small subsidy amounts and are thus included here. Cost and water savings (Table 3) ranges represent the $10^{\text {th }}$ and $90^{\text {th }}$ percentiles for Amman households willing to accept. The work did not show piped water charges avoided by accepting customers; instead, we use the median marginal price (JD 0.5/ $\mathrm{m}^{3}$ ) to estimate the lost revenue or water system operation cost.

Re-price water. The detailed Amman study also showed an inelastic residential price response with elasticity estimated at between -0.025 and -0.035 (Rosenberg et al. 2007). This elasticity means that doubling the average charge for piped water would only reduce piped water use by about $2.5 \%$. As a conservation program, re-pricing water may achieve 
small water savings. However, raising prices represents an opportunity to increase revenues and pass more production, treatment, and delivery costs onto customers. In Amman, instituting a new price schedule requires approval by parliament and is politically difficult. We include this action primarily for demonstration purposes. We estimate capital costs for publicity, accounting, and staff retraining.

Increase meter registration. Bench top tests show that "rolled" class B water meters (improperly rotated by up to 90 degrees to ease reading) under-register customer water use by $11 \%$ to $14 \%$ (Griffen 2004). Retrofitting the estimated 10\% of rolled meters with any-position meters can increase registration and system revenue but will not save water. We estimate capital costs based on an installation charge of JD 25 per meter.

Meter illegal connections. Unauthorized use (theft) is a significant (but unknown) component of apparent losses. Installing meters on illegal connections could increase system revenues and slightly reduce use. Here, we assume metering would counteract $10 \%$ to $15 \%$ of existing apparent losses, that thieving and legitimate customers consume similar water volumes, and that thieving customers will maintain their use patterns after metering. The life span is lower (compared to increasing meter registration) since thieving customers are more likely to subvert meter installations.

\section{Short-term conservation}

Short-term conservation actions have an immediate and therefore flexible effect to reduce system water use. They can be implemented as needed, in response to events.

Reduce response time to fix leaks. Reducing the time to fix reported leaks can save significant water volumes. Given LEMA's recent efforts in this area, we assume an annual budget of JD 1 million could mobilize savings between 5\% and 10\% of the current system physical leakage. Note, restructuring the distribution system will reduce spontaneous leakage and the water saved by faster leak repair. 
Restrict outdoor water use. Many cities have significantly reduced water use in droughts by restricting outdoor watering (Kenny et al. 2004). In Amman, few customers have gardens or lawns, the operator has never imposed restrictions, outdoor water use is primarily to wash cars and irrigate landscaping and is a small part of aggregate water use. We use results from the detailed Amman study (Rosenberg et al. 2007) to set seasonal upper limits when restricting outdoor water use. Operation costs are lost revenues and reflect the range of piped water costs avoided by customers with outdoor use should restrictions become active. A customer conservation program and rebates to install drip irrigation will reduce water saved by restricting outdoor water use.

Disconnect illegal connections. Currently, LEMA employs 40 staff to visit customers with unpaid bills and disconnect those who refuse to pay (Griffen 2004). The team also uses maps and other means to identify and disconnect households with illegal connections or customers who bypass their meters. The team disconnects about 700 households per month with reported real water savings of $7 \mathrm{Mm}^{3} /$ year and operation costs reflecting salaries and durables to support the team. However, the lasting effects are short. Disconnection may motivate a customer to make another illegal connection; the fraction of repeat offenders is unknown.

Ration service. The Amman water system operator can significantly reduce customer piped water use by rationing the time water is available in the distribution system. Rationing is also an extreme form of pressure management to reduce physical leakage and apparent losses. Customers respond by using alternative sources (rainwater, greywater, or vendors who sell water from private wells) or adopting long- and/or short-term conservation behaviors. Currently, the Amman water system operator rations water so it is available to customers for only 24 to 60 hours per week. Here, we divide rationing into two tiers. Tier 1 represents normal rationing with limited customer responses. In this tier, operation costs are nil (input as a very small, positive number) and the upper limit is 15\% to $25 \%$ of the total system input, or the estimated untapped demand not met because of 
existing rationing. Tier 2 represents severe rationing that requires drastic customer responses, and is the "action of last resort”. In tier 2, the upper limit is unlimited, but operation costs skyrocket to the exorbitant prices charged by private tanker trucks to customers during the most severe water shortages on record. In actuality, customersrather than the system operator-bear these costs. However, the tier 2 rationing cost should be interpreted as the "penalty" the municipal water system incurs when it otherwise fails to balance supplies and demand.

\subsection{Shortage Events}

We develop shortage events for year 2020 from uncertain (i) surface water runoff, and (ii) forecasts of municipal water demand. Here, we use 65 years (1937 to 2002) of modeled runoff in the North Rift side wadis, Yarmouk, and Amman-Zarqa basins (Taha and Magiera 2003) to characterize the probability distribution of uncertain surface water availability to Amman. We describe uncertain demands for Amman as a uniform probability distribution between 191 and $251 \mathrm{Mm}^{3} /$ year reflecting high and low demand forecasts reported in the Jordan water literature for 2020 (Alkhaddar et al. 2005; Al-Salihi and Himmo 2003; Fisher et al. 2005; Mohsen and Al-Jayousi 1999; Taha and Magiera 2003). In select cases, Kingdom-wide demand forecasts (all sectors) were prorated by $27 \%$ to obtain municipal sector demand and by $34.6 \%$ to obtain demand for Amman. Convoluting the difference between uncertain demand forecast, uncertain surface water availability, existing fixed groundwater availability, and the additional fixed untapped demand not met because of existing rationing gives the probability distribution of annual shortages (Jaynes 2003; Rosenberg 2007). We characterize the shortage distribution using a discrete set of 6 annual shortage levels and mass probabilities to represent explicit shortage events (Table 4). In the modeling, we prorate each annual shortage level into seasonal volumes (summer and winter) based on average seasonal allocations to Amman reported over the past decade (WAJ, 1994-2004). We include unmet demand due to existing rationing as part of shortages (and allow it be met at no cost by tier 1 rationing) 
so that we can later parametrically reduce the upper limit on tier 1 rationing to study impacts on water availability.

\subsection{Solution method}

The stochastic programs were coded in the Generic Algebraic Modeling System (GAMS) and solved with BDMLP (Brooke et al. 1998). The deterministic-equivalent program used point values that were the midpoints of the ranges reported in Tables $2-4$. The robust program used 20 data scenarios. Each parameter value was randomly and independently sampled in GAMS from a uniform distribution between reported ranges. These ranges were also inputs for the grey-number and best/worst case formulations.

A base case used uncertain demand forecasts for year 2020. Input data was organized and managed in Excel, then written to text files read by GAMS. Optimization results were written out to Excel for post processing and visualization. Run time for all models was less than 2 minutes on a Pentium laptop.

\section{Results and Discussion}

We present base case results for 2020 and draw comparisons among the four approaches to include uncertainties (Tables 5 and 6). Two parametric extensions also show effects of (i) increasing shortage levels to levels forecast for 2040 (Figure 4) and (ii) decreasing the upper limit of tier 1 rationing (Figure 5). Discussion highlights suggestions to expand capacity over time and increase water availability to customers. We compare these suggestions to current and planned MWI and LEMA actions and results from a prior regional optimization study (Fisher et al. 2005).

\subsection{Base case: coping with shortages in 2020}

The four modeling approaches recommend a nearly identical mix of long-term supply enhancement and conservation actions (Table 5). Particularly, that implementing most conservation actions combined with maximum allowable new surface and local 
groundwater supplies, building small plants to desalinate distant brackish waters, purchasing additional mobile desalination units, and expanding capacity at Zai to treat and convey additional surface water to Amman can forestall the mega projects (RedDead seawater desalination, distant Disi groundwater pumping, and desalinating the brackish Zara-Ma’een waters). Expected annual costs are consistent but large-implying, minimally, present value investments of JD 660 to 800 million to cope with shortages.

The robust and deterministic-equivalent solutions differ only in that the robust solution builds one additional plant to desalinate distant brackish waters and purchases one more mobile desalination unit. These additions constitute only JD 7 million/year difference in expected annual costs and are small because the ranges of parameter values considered in the robust data scenarios are close to the average parameter values used in the deterministic-equivalent formulation.

Expected annual costs for the deterministic-equivalent and robust solutions also fall within the ranges indicated by the best / worst case analysis. However, the grey number solution does not. In fact, the upper-bound grey-number solution is JD 280 million per year-higher (worse) than the worst-case analysis! This result occurs for three reasons. First, the grey-number solution recommends a smaller program of long-term actions to reduce costs under favorable economic conditions. This program is also recommended by the best-case analysis and builds fewer plants to desalinate distant brackish water, does not purchase mobile desalination units, or implement the Capital Investment Program to curtail physical water loss. Second, the grey-number approach must implement the same reduced program of long-term actions under unfavorable conditions to maintain feasible ranges for decisions across sub-models. This sub-model interaction means the greynumber approach has fewer options to cope with larger shortfalls. It requires many additional and more costly short-term actions (see severe rationing (R2) in Table 6). And third, the worst-case analysis is not similarly constrained. Under unfavorable conditions, the worst-case basis for long-term actions switches to exclude many conservation actions 
and increase use of distant groundwater, local and distant brackish waters, and mobile desalination units. The best/worst case solution identifies contrasting approaches to operate the system under favorable and unfavorable circumstances whereas the greynumber solution incurs significant costs (above worst case estimates) to maintain stable, feasible ranges for solutions.

In sum, the long-term action results highlight several important distinctions among the four approaches to consider uncertainties. First, the grey-number solution is risk prone. Second, the best / worst-case analysis can suggest conflicting-rather than systematicresponses. And third, deterministic-equivalent and robust approaches seem to offer single, coherent responses at moderate costs.

Otherwise, the four approaches recommend similar mixes of and levels for short-term actions (Table 6). All formulations suggest regularly disconnecting illegal users, not renting tanker trucks, and increasing levels of implementation for the other short-term actions as shortage events become more severe. They also show good agreement regarding the shadow values of constraints on Zai treatment and conveyance capacity (Eqs. 1e, 2e, and 3e; results not shown). Namely, capacity (even with expansion) is still limited or nearly limited in the largest shortage events (the events that require tier 2 rationing). These results suggest that expanding Zai capacity beyond the planned upgrade can further reduce shortage costs. This expansion becomes more cost effective should more Jordan Valley surface water become available.

\subsection{Parametric Analysis}

\subsubsection{Capacity expansion over time}

Resolving the deterministic-equivalent optimization program for the shortages with uncertain demands predicted for 2040 (Al-Salihi and Himmo 2003) shows the capital investments required to accommodate future expanded shortages (Figure 4). Four main trends over time are apparent. 
1. Fast rising costs. Expected annual costs rise from about JD 33 million per year through 2020 to more than JD 132 million per year in 2040. The expected annual shortage level triples whereas costs quadruple. In later years, only expensive new supply options are still available.

2. Growing importance of conservation. Water saved by reducing physical leakage and targeting customers to install water efficient appliances grows as demand increases. These actions show important economies of scale and significantly dampen cost trend \#1 above. Investing early in water conservation makes it possible to later reap expanded savings as demand grows with little added cost.

3. Delayed need for mega projects for new supply. Pumping distant groundwater (Disi Conveyor) and desalinating local brackish water (Zara Ma’een) only become cost-effective options to cope with shortages in 2040.

4. Little role for seawater desalination. Even the worst-case analysis does not suggest building the Red-Dead Canal. Instead, a wide mix of other, less expensive options are available and should provide required water volumes and reliabilities through 2040. However, further sensitivity analysis shows that the Red-Dead Canal may become feasible should it’s capital cost decrease to JD 56 million (82\% to $98 \%$ reduction). This large reduction is partly related to the project's high operational costs. We can also interpret the sensitivity results to mean: build the Red-Dead Canal if the project’s environmental, hydropower, and other nonAmman water supply related benefits instead justify the project costs.

\subsubsection{Increasing water availability to customers}

A second set of runs resolved the base case deterministic-equivalent formulation with a higher water demand level while parametrically decreasing the upper limit for tier 1 rationing to zero. This analysis identifies costs and actions to increase water availability 
to customers (Figure 5). We post-calculate availability by reworking the component analysis (Figure 3) considering the new actions to secure supplies and reduce real and apparent losses. Availability is then billed use divided by forecast number of customers.

Figure 5 shows expected annual costs double as availability increases from the base case level of 200 towards $260 \mathrm{~m}^{3}$ per customer per year. Several new supplies increase availability: first the Zara-Ma'een project, later the Disi aquifer conveyor, and finally both. However, both projects are expensive. Real and accounting losses are significant and consume part of the new supplies. This shows a steep water-supply function.

\subsection{Comparing to actions already underway and results from a prior study}

MWI and LEMA will shortly open the Zara-Ma'een project to desalinate and convey nearby brackish water and have nearly completed the project to reduce physical water loss from the Amman distribution network. MWI plans to expand Zai plant capacity and is tendering proposals to build the Disi aquifer conveyor. Elsewhere, MWI and USAID are jointly tendering proposals for a second Kingdom-wide water conservation program while LEMA has aggressively pursued a physical and accounting loss reduction program. The program has reduced response time to fix reported leaks, retrofitted "rolled” meters, and metered or disconnected illegal connections.

Our results show each action is an important long-term investment for MWI and LEMA to proactively address current and future water shortages. The Zai expansion, physical and accounting water loss reduction programs, and conservation targeted to customers are urgently needed. Zara-Ma’een desalination and Disi groundwater are needed later on. The parametric results confirm that Zara-Ma'een is the low-cost option to increase availability to Amman.

Although MWI is developing plans to desalinate and convey Red Sea water via the Dead Sea, our results show this project is a less urgent and a more costly way to address 
shortages through 2040. Desalinating distant brackish waters, targeting conservation programs to specific customers, restructuring the network, reducing the response time to fix reported leaks, and other actions should provide sufficient water quantities at suitable reliabilities and lower costs. However, the Red-Dead Canal may merit consideration if its other non-water supply benefits justify nearly all the capital costs.

Our findings also largely affirm and expand upon results from a prior regional-scale, single-year, benefit-maximizing, deterministic optimization study for Jordan (Fisher et al. 2005, chapter 7). Namely, urgent needs to (i) expand the Zai treatment and conveyance capacity (Balqa to Amman conveyor), (ii) reduce physical water loss (intra-district leakage), and (iii) only build the Red-Dead canal should environmental and other benefits justify the capital costs. Fisher et al. (2005) show that the Zara-Ma'een and Disi mega projects can reduce scarcity costs in Amman, but do not resolve project timings. Their regional focus also show effects in other districts whereas our city-scale focus permits including systematic effects of uncertainties and conservation actions like reducing accounting losses, targeting select customers to install water efficient appliances, and offering rebates to motivate additional installations. We leave for further study comparing these actions with other new supply and conservation actions potentially taken at the regional scale (actions like tax incentives to encourage customers to install water efficient appliances, import restrictions on water-wasting appliances, labeling water-efficient appliances, etc).

\section{Conclusions}

Stochastic programming identifies an optimal mix of long- and short-term supply enhancement and conservation actions to cost-effectively respond to a distribution of water shortages. Deterministic-equivalent, robust, grey-number, and best/worst case formulations showcase different approaches to systematically include uncertainties. 
The four approaches offer remarkably similar suggestions to address shortages forecast for Amman, Jordan in 2020. Key differences are (i) the grey-number solution is riskprone-potentially gives higher costs than the worst-case analysis, and (ii) best / worstcase analysis offers conflicting strategies. Further research should identify new greysolution algorithms that are risk-adverse.

The results also suggest four strategies to help Amman managers cope with shortages:

1. Conserve water now. Reduce physical leakage, target awareness to select customers to install water efficient appliances, and offer rebates to motivate other customers to follow suit. Water savings should grow over time at little added cost as demand increases.

2. Delay implementing mega projects for new supplies such as desalinating the brackish Zara-Ma'een waters and pumping the Disi aquifer to later years,

3. Significantly delay desalinating seawater (Red-Dead Canal) given the availability of cheaper new supplies and alternatives to reduce billed water use, physical, and accounting losses.

4. Build the Zara-Ma'een project as the low-cost option to increase water availability to customers.

Overall, our analysis shows that shortages pose a major and growing problem in Amman. Addressing shortages will require significant capital investments. Increasing water availability to customers will require still further investments.

\section{Acknowledgements}

Mr. Rosenberg is supported by a U.S. National Science Foundation graduate research fellowship. The authors thank Frank Fisher, Richard Howitt, Mimi Jenkins, Hani AbuQdais, and two anonymous reviewers for comments on earlier drafts. 
Rosenberg \& Lund,WARM332, Feb 13, 2008

\section{References}

Abu-Taleb MF, Murad MM (1999) Use of focus groups and surveys to evaluate water conservation campaign. Journal of Water Resources Planning and ManagementAsce 125(2):94-99

Alkhaddar RM, Sheehy WJS, Al-Ansari N (2005) Jordan's Water Resources: Supply and Future Demand. Water International 30(3):294-303

Al-Salihi AH, Himmo SK (2003) Control and Management Study of Jordan's Water Resources. Water International 28(1):1-10

Brooke A, Kendrick D, Meeraus A et al (1998) GAMS, a user's guide, GAMS Development Corporation, Washington, D.C.

El-Nasser H (2005), Amman, Jordan

Faruqui N, Al-Jayyousi O (2002) Greywater reuse in urban agriculture for poverty alleviation - A case study in Jordan. Water International 27(3):387-394

Fisher FM, Huber-Lee A, Amir I et al (2005) Liquid Assets: An economic approach for water management and conflict resolution in the Middle East and beyond. Resources for the Future, Washington, D.C.

Garcia-Alcubilla R, Lund JR (2006) Derived willingness-to-pay for household water use with price and probabilistic supply. Journal of Water Resources Planning and Management-Asce 132(6):424-433

Griffen R (2004) Management of Water Losses Due to Commercial Reasons: A Study in Amman. Paper presented at the International Water Demand Management Conference, Dead Sea, Jordan, June 2004.

Huang GH, Baetz BW, Patry GG (1994) Grey Dynamic-Programming for WasteManagement Planning under Uncertainty. Journal of Urban Planning and Development-Asce 120(3):132-156

Huang GH, Baetz BW, Patry GG (1995) Grey Integer Programming - an Application to Waste Management Planning under Uncertainty. European Journal of Operational Research 83(3):594-620

Huang GH, Loucks DP (2000) An inexact two-stage stochastic programming model for water resources management under uncertainty. Civil Engineering and Environmental Systems 17(2):95-118

Hussein IAJ (2000) Managing water supply systems under sudden disasters: Jordan during the Gulf War (1990-1991). Water International 25(2):232-237

IdRC (2004) A Survey of Home Appliances and Toilets in the Jordanian Markets, Academy for Educational Development: Water Efficiency for Public Information and Action (WEPIA) Program, Amman, Jordan

Ishibuchi H, Tanaka H (1990) Multiobjective Programming in Optimization of the Interval Objective Function. European Journal of Operational Research 48(2):219-225

Jaber JO, Mohsen MS (2001) Evaluation of non-conventional water resources supply in Jordan. Desalination 136(1-3 SU):83-92

Jaynes ET (2003) Probability Theory: the logic of science. Cambridge University Press, Cambridge, United Kingdom 
Jenkins MW, Lund JR (2000) Integrating yield and shortage management under multiple uncertainties. Journal of Water Resources Planning and Management-Asce 126(5):288-297

Joench-Clausen T, Fugl J (2001) Firming up the Conceptual Basis of Integrated Water Resources Management. International Journal of Water Resources Development 17(4):501-510

Kenny DS, Klien RA, Clark MP (2004) Use and effectiveness of municipal water restrictions during drought in Colorado. Journal of the American Water Resources Association 40(1):77-87

Li YP, Huang GH, Nie SL (2006) An interval-parameter multi-stage stochastic programming model for water resources management under uncertainty. Advances in Water Resources 29(5):776-789

Lund JR (1995) Derived estimation of willingness to pay to avoid probabilistic shortage. Water Resources Research 31(5):1367-1372

Maqsood M, Huang GH (2003) A two-stage interval-stochastic programming model for waste management under uncertainty. Journal of the Air \& Waste Management Association 53(5):540-552

Mohsen MS, Al-Jayousi OR (1999) Brackish water desalination: an alternative for water supply enhancement in Jordan. Desalination 124:163-174

Mulvey JM, Vanderbei RJ, Zenios SA (1995) Robust optimization of large-scale systems. Operations Research 43(2):264-281

Nuaimat K, Ghazal M (2006) Water will be in abundance by 2020 - minister. Jordan Times, Amman

Rosenberg DE (2007) Probabilistic Estimation of Water Conservation Effectiveness. Journal of Water Resources Planning and Management 133(1):39-49

Rosenberg DE, Talozi S, Lund JR (in press) Intermittent Water Supplies: Challenges and Opportunities for Residential Water Users in Jordan. Water International

Rosenberg DE, Tarawneh T, Abdel-Khaleq R et al (2007) Modeling Integrated WaterUser Decisions in Intermittent Supply Systems. Water Resources Research 43(7):W07425.10.1029/2006WR005340

Sahinidis NV (2004) Optimization under uncertainty: state-of-the-art and opportunities. Computers \& Chemical Engineering 28(6-7):971-983

Scott CA, El-Haser H, Hagan RE et al (2003) Facing Water Scarcity in Jordan: Reuse, Demand Reduction, Energy, and Transboundary Approaches to Assure Future Water Supplies. Water International 28(2):209-216

Sen S, Higle JL (1999) An introductory tutorial on stochastic linear programming models. Interfaces 29(2):33-61

Taha S, Magiera P (2003) National Water Master Plan: Water Resources in Jordan, Ministry of Water and Irrigation, Amman, Jordan

Thomas JS, Durham B (2003) Integrated Water Resource Management: looking at the whole picture. Desalination 156(1-3):21-28

WEPIA (2000) Assessment of Water Saving Devices Sector in Jordan, Amman, Jordan Wilchfort O, Lund JR (1997) Shortage management modeling for urban water supply systems. Journal of Water Resources Planning and Management 123(4):250-258 
Rosenberg \& Lund,WARM332, Feb 13, 2008

Wolf AT, Murakami M (1995) Techno-political decision making for water resources development: the Jordan River watershed. Water Resources Development 11(2):147-161 

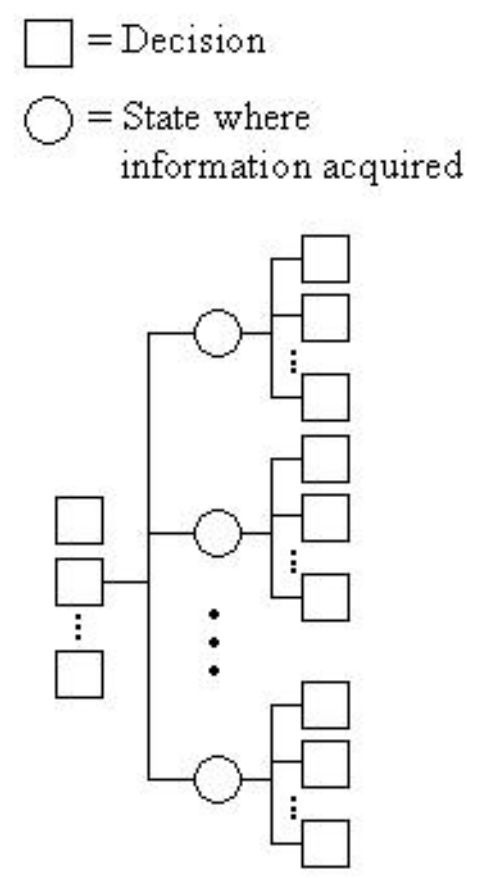

$1^{\text {st }}$
Stage Event $\begin{gathered}2^{\text {nd }} \\ \text { Stage }\end{gathered}$

\section{A. Deterministic} Formulation

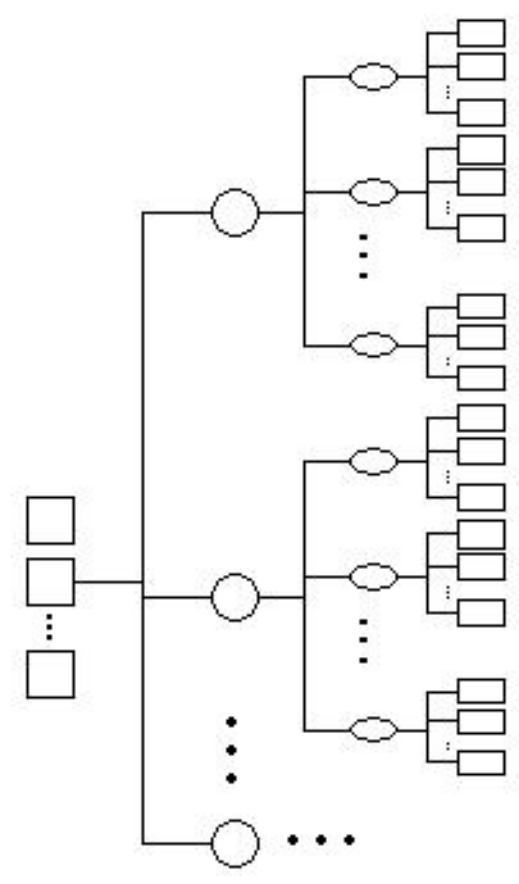

$\begin{array}{cc}1^{\text {st }} & \text { Data } \\ \text { Stage } & \text { Scenario Event } \\ \text { Stage } & 2^{\text {nd }} \\ \end{array}$

B. Robust

Formulation
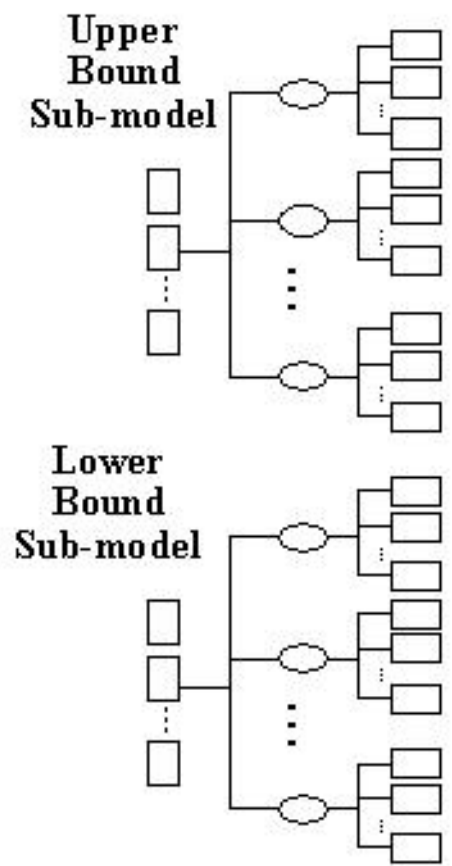

$$
\begin{gathered}
1^{\text {st }} \\
\text { Stage }
\end{gathered} \text { Event } \begin{gathered}
2^{\text {nd }} \\
\text { Stage }
\end{gathered}
$$

C. Grey Number Formulation

Figure 1. Decision trees for stochastic programs with recourse 


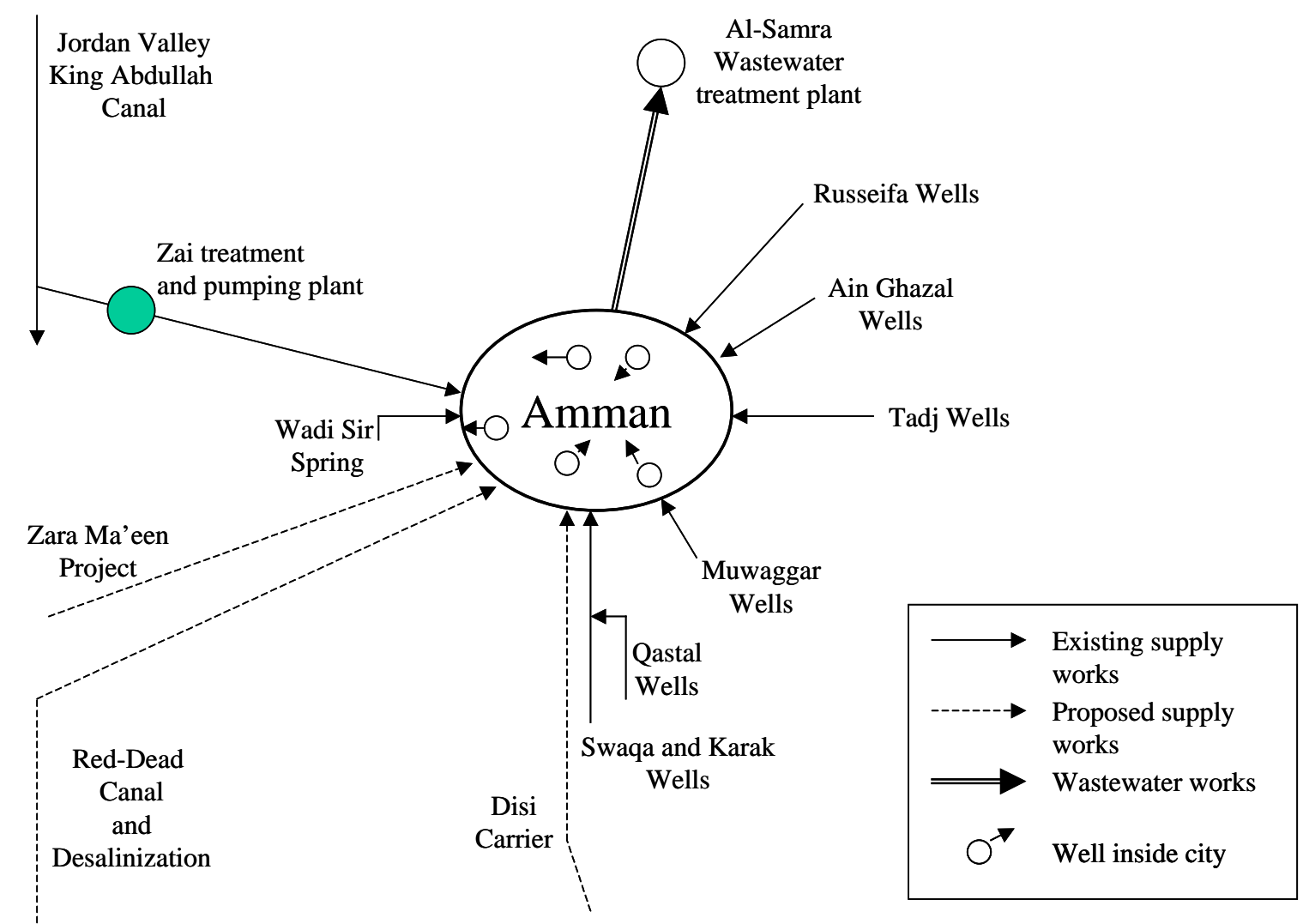

Figure 2. Schematic of existing and proposed main water supply and wastewater works for Amman 


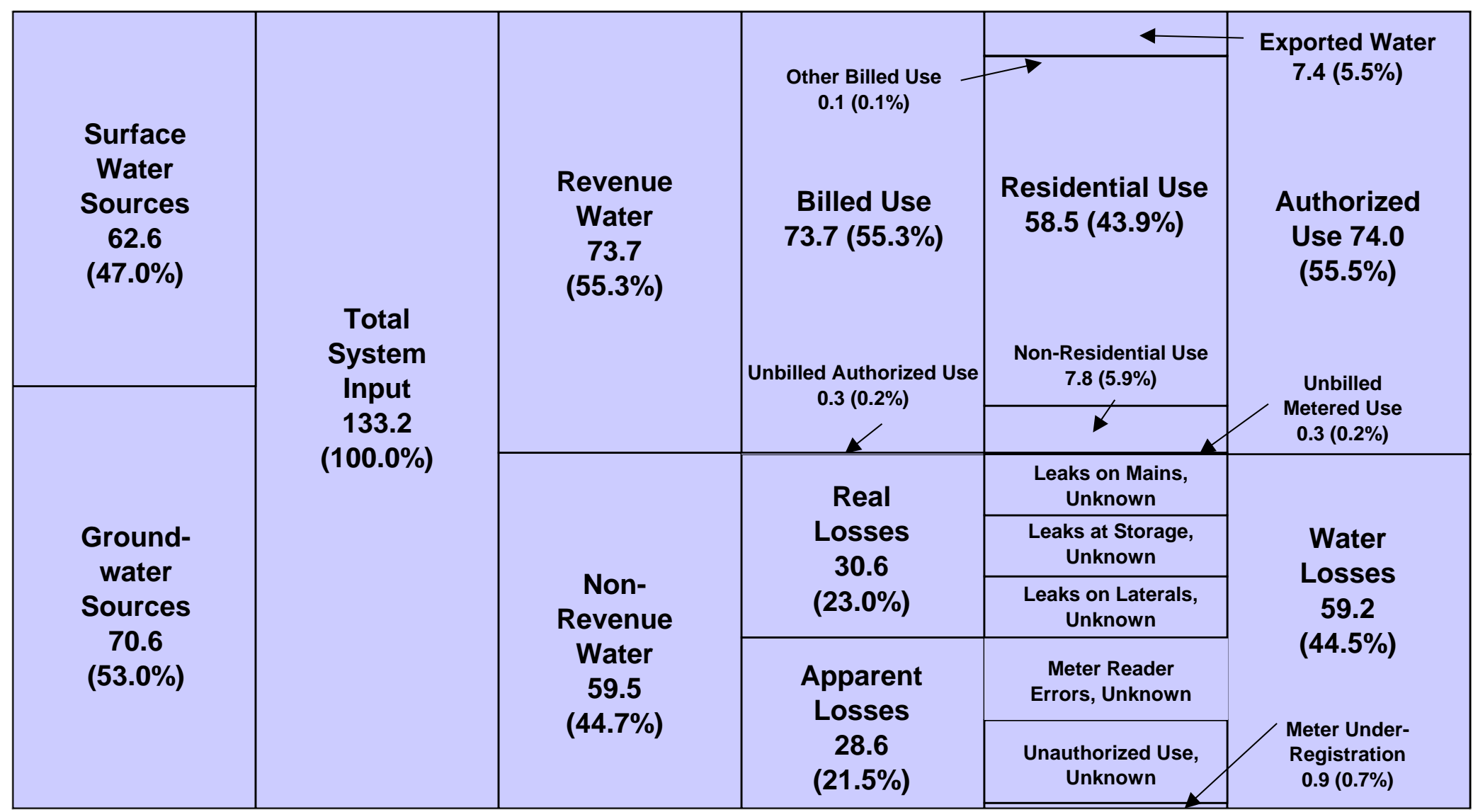

Figure 3. Component analysis for Amman, Jordan water system (2005) $\mathrm{Mm}^{3}$ per year (\% of total system input) 


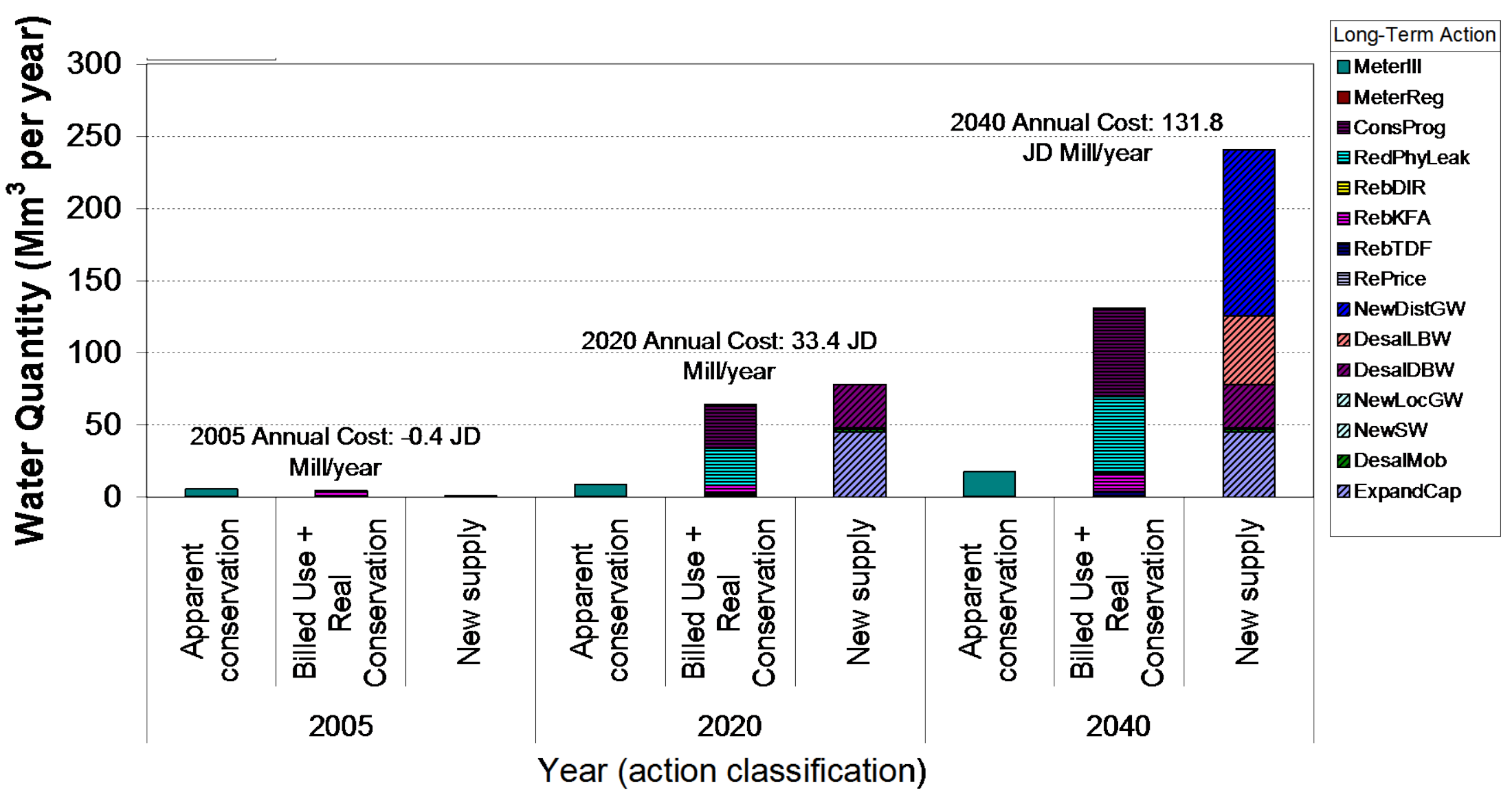

Figure 4. Capacity expansion and expected costs to cope with shortages over time 


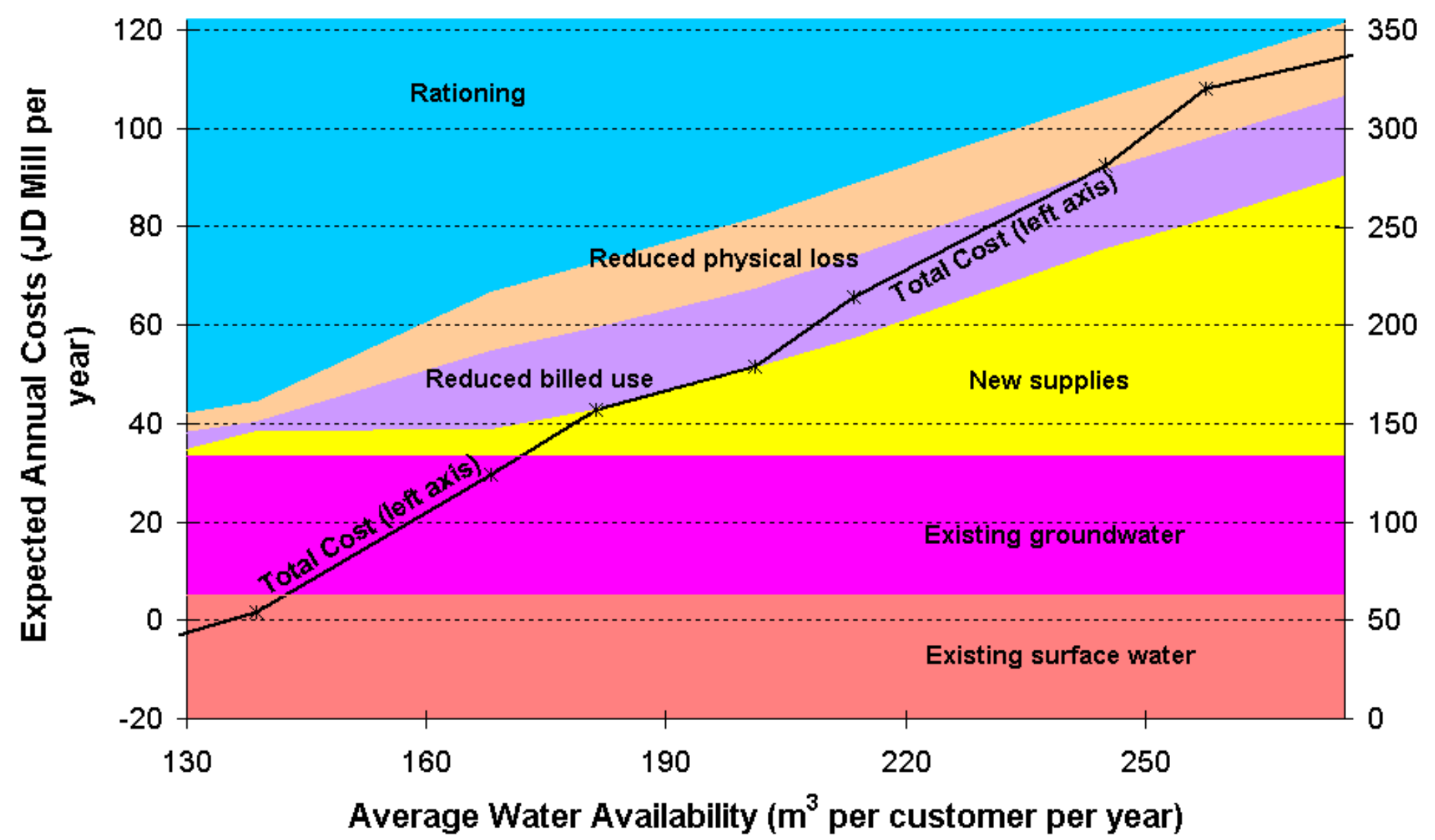

Figure 5. Costs associated with increasing water availability to customers 


\section{Table 1. Municipal water system shortage management actions}

\begin{tabular}{|c|c|c|c|c|}
\hline \multirow{2}{*}{ Stage } & \multirow{2}{*}{ Supply Enhancement } & \multicolumn{3}{|c|}{ Conservation / Demand Reduction } \\
\hline & & Real Losses & Billed Use & Apparent Losses \\
\hline $\begin{array}{c}\text { Long- } \\
\text { term }\end{array}$ & $\begin{array}{ll}\text { - } & \text { Expand wastewater recycling and } \\
\text { - } & \text { reuse capacity } \\
\text { - } & \text { Develop new surface water (dams) } \\
\text { - } & \text { Develop new local groundwater } \\
\text { - } & \text { Expand system storage, conveyance, } \\
\text { and treatment } \\
\text { - Build desalination plants } \\
\text { - Seawater } \\
\text { - Brackish waters } \\
\text { - Mobile units } \\
\text { - } \text { Purchase tanker trucks }\end{array}$ & $\begin{array}{l}\text { - Restructure } \\
\text { distribution system } \\
\text { - Lower } \\
\text { operating } \\
\text { pressure } \\
\text { - Optimize and } \\
\text { control flows }\end{array}$ & $\begin{array}{l}\text { Promote water } \\
\text { efficient } \\
\text { landscaping and } \\
\text { appliances, grey- } \\
\text { water reuse, and } \\
\text { rainwater } \\
\text { collection } \\
\text { - Rebates to } \\
\text { customers to install } \\
\text { water efficient } \\
\text { appliances } \\
\text { Re-price water }\end{array}$ & $\begin{array}{ll}- & \text { Retrofit under- } \\
& \text { registering meters } \\
\text { - } & \text { Incentives to } \\
& \text { meter-readers and } \\
\text { bill collectors } \\
\text { - } & \text { Install meters on } \\
& \text { illegal connections }\end{array}$ \\
\hline $\begin{array}{c}\text { Short- } \\
\text { term }\end{array}$ & $\begin{array}{ll}\text { - } & \text { Buy Agricultural water during } \\
\text { - } & \text { Enhaughts or shortages (fallowing) } \\
\text { - } & \text { Deliver water by tanker truck } \\
\text { - Trucks owned by water system } \\
\text { - Rent trucks } \\
\text { - Use surface water } \\
\text { - Use local groundwater } \\
\text { - Use distant groundwater } \\
\text { - } \quad \text { Reuse wastewater } \\
\text { - Use desalination plants (seawater, } \\
\text { brackish waters, mobile units) }\end{array}$ & $\begin{array}{ll}\text { - } & \text { Detect and repair } \\
\text { network leaks } \\
\text { - } \\
\text { Decrease response } \\
\text { time to fix leaks } \\
\text { - } \\
\text { Ration service } \\
\text { - Tier } 1 \\
\text { - Tier } 2\end{array}$ & $\begin{array}{l}\text { - } \begin{array}{l}\text { Disconnect illegal } \\
\text { users }\end{array} \\
\text { - } \quad \text { Restrict outdoor } \\
\text { water uses } \\
\text { - Car washing } \\
\text { - Irrigation } \\
\text { - } \quad \text { Ration service } \\
\text { - Tier } 1 \\
\text { - Tier } 2\end{array}$ & $\begin{array}{c}\text { - } \\
\text { Ration service } \\
\text { - Tier } 1 \\
\text { - Tier } 2\end{array}$ \\
\hline
\end{tabular}


Table 2. Potential long-term actions for Amman, Jordan

\begin{tabular}{|c|c|c|c|c|c|c|}
\hline Action & $\begin{array}{c}\text { Capital Cost } \\
\text { (JD Mill) }\end{array}$ & $\begin{array}{c}\text { Lifespan } \\
\text { (Years) }\end{array}$ & $\begin{array}{l}\text { Water Quantity } \\
\text { (MCM/year) }\end{array}$ & $\begin{array}{c}\text { Operating } \\
\text { Cost }\left(\mathrm{JD} / \mathrm{m}^{3}\right) \\
\end{array}$ & Notes & Source \\
\hline \multicolumn{7}{|l|}{ Water Supply Enhancement } \\
\hline 1. New surface water sources & 0.01 to 0.04 & 15 to 30 & 0.01 to 0.04 & 0.02 to 0.18 & $\begin{array}{l}\text { Only small, distant desert } \\
\text { impoundments }\end{array}$ & JVA, 2005 \\
\hline 2. New local groundwater sources & 0.005 to 0.045 & 5 to 15 & 0.1 to 0.4 & 0.035 to 0.05 & $\begin{array}{l}\text { Per well; Drilling, pumping, and } \\
\text { bacteological treatment }\end{array}$ & WAJ, 2004 \\
\hline 3. New distant groundwater sources & 600 & 20 to 30 & 80 to 150 & 0.21 & Disi aquifer pumping and pipeline & $\begin{array}{l}\text { El-Nasser, 2005; Nuaimat } \\
\text { and Ghazal, } 2006\end{array}$ \\
\hline 4. Build sea-water desalination plant & 1,420 to 2,130 & 15 to 25 & 850 & 1.15 & Red-Dead project & $\begin{array}{l}\text { El-Nasser, 2005; Nuaimat } \\
\text { and Ghazal, } 2006\end{array}$ \\
\hline 5. Desalinate local brackish water & 125 & 10 to 20 & 35 to 60 & 0.30 to 0.33 & Zara Ma'een project & $\begin{array}{l}\text { WAJ, 2005; Nuaimat and } \\
\text { Ghazal, } 2006\end{array}$ \\
\hline 6. Desalinate distant brackish waters & 0.1 to 3.5 & 10 to 20 & 0.6 to 6.1 & 0.30 to 0.40 & Per plant; as for existing plants & WAJ, 2005 \\
\hline 7. Buy mobile desalination unit & 0.088 to 0.090 & 5 to 15 & 0.438 & 0.32 to 0.37 & Per unit; salinity up to $4000 \mathrm{PPM}$ & WAJ, 2005 \\
\hline 8. Buy new water tanker truck & 0.033 to 0.045 & 5 to 15 & 0.006 to 0.015 & 0.76 to 2.02 & Per truck; as for existing trucks & LEMA, 2006 \\
\hline $\begin{array}{l}\text { 9. Expand capacity to store, convey, } \\
\text { and treat water }\end{array}$ & 45 to 71 & 10 to 20 & 45 & 0.16 & $\begin{array}{l}\text { Zai pumping and treatment plant } \\
\text { expansion }\end{array}$ & $\begin{array}{l}\text { Fisher et al, 2005; USAID, } \\
2005\end{array}$ \\
\hline $\begin{array}{l}\text { 10. Expand capacity to recycle and } \\
\text { reuse wastewater }\end{array}$ & 49 to 108 & 10 to 20 & 7 to 58 & 0.01 to 0.26 & $\begin{array}{l}\text { Al-Samra expansion, Wadi Zarka, and } \\
\text { South Amman treatment plants }\end{array}$ & $\begin{array}{l}\text { WAJ, 2004; Taha and } \\
\text { Magiera, } 2003\end{array}$ \\
\hline \multicolumn{7}{|l|}{ Water Demand Management } \\
\hline 11. Physical loss reduction ${ }^{\mathrm{a}}$ & 142 & 10 to 30 & 10.7 to 20.7 & 0.05 to 0.19 & $\begin{array}{l}\text { Capital Improvement Project to } \\
\text { restructure Amman network }\end{array}$ & MWI, 2005 \\
\hline $\begin{array}{l}\text { 12. Customer water conservation } \\
\text { program }^{\mathrm{a}}\end{array}$ & 2 to 9 & 2 to 10 & 10.5 to 26.3 & 0.14 to 1.13 & $\begin{array}{l}\text { Target water efficient appliances to } \\
\text { customers with potential to save most } \\
\text { water and money }\end{array}$ & Rosenberg et al., 2006 \\
\hline \multicolumn{7}{|c|}{ 13. Offer rebates to customers who adopt conservation technologies } \\
\hline - Dual flush toilets ${ }^{a, b}$ & 0.04 to 0.47 & 3 to 7 & 0.3 to 1.5 & 0 & Ranges from 10th and 90th percentiles & Rosenberg et al., 2006 \\
\hline - Kitchen faucet aerators ${ }^{\mathrm{a}, \mathrm{b}}$ & 0.10 to 2.12 & 3 to 5 & 0.3 to 6.9 & 0 & of Monte-Carlo simulated Amman & Rosenberg et al., 2006 \\
\hline - Drip irrigation ${ }^{\mathrm{a}, \mathrm{b}}$ & 0.02 to 0.09 & 3 to 7 & 0.0 to 0.4 & 0 & households & Rosenberg et al., 2006 \\
\hline 14. Re-price water ${ }^{\mathrm{a}}$ & 0.5 to 1.5 & 2 to 5 & 0.1 to 0.5 & -7.2 to -13.4 & $\begin{array}{l}\text { Uses reported elasticity and average } \\
\text { aggregate price increase from JD } 0.02 \\
\text { to } 0.10 \text { per m3. Politically difficult }\end{array}$ & Rosenberg et al., 2006 \\
\hline 15. Increase meter registration & 0.8 to 0.9 & 3 to 10 & 0.7 to 0.8 & -0.45 to -0.55 & Retrofit rolled meters; JD 25 / meter & LEMA, 2004; 2005; 2006 \\
\hline 16. Meter illegal connections $\mathrm{a}^{\mathrm{a}, \mathrm{b}}$ & 0.7 to 0.9 & 1 to 5 & 4.3 to 5.7 & -0.45 to -0.55 & JD 25 / meter & LEMA, 2005 \\
\hline
\end{tabular}

a. Water quantity scales with demand forecast

b. Capital cost scales with demand forecast 
Table 3. Potential short-term actions for Amman, Jordan

\begin{tabular}{|c|c|c|c|c|c|}
\hline \multirow{2}{*}{ Action } & \multicolumn{2}{|c|}{ Upper Limit (MCM/year) } & \multirow{2}{*}{$\begin{array}{c}\text { Operating } \\
\text { Cost }\left(\mathrm{JD} / \mathrm{m}^{3}\right)\end{array}$} & \multirow{2}{*}{ Notes } & \multirow{2}{*}{ Source } \\
\hline & Summer & Winter & & & \\
\hline \multicolumn{6}{|l|}{ Water Supply Enhancement $^{\mathrm{a}}$} \\
\hline $\begin{array}{l}\text { 1. Buy agricultural water during } \\
\text { drought }\end{array}$ & 6.4 & 0 & 0.20 to 0.22 & $\begin{array}{l}\text { Rent land from Jordan valley farmers } \\
\text { (fallowing program) }\end{array}$ & JVA, 2005 \\
\hline 2. Enhance precipitation & 0 & 30.48 & 0.25 to 0.26 & $\begin{array}{l}\text { Pilot cloud seeding tests in N. Jordan in } \\
\text { 1992; assume increase SW by } 12 \%\end{array}$ & Taha and Magiera, 2003 \\
\hline 3. Rent tanker trucks & 0.003 to 0.008 & 0.003 to 0.008 & 0.40 to 1.07 & Per truck & LEMA, 2005 \\
\hline \multicolumn{6}{|l|}{ Water Demand Management } \\
\hline 5. Restrict outdoor water use $\mathrm{b}^{\mathrm{b}, \mathrm{c}}$ & 3.2 to 5.5 & 0.8 to 1.4 & 0.56 to 0.62 & Landscape irrigation, car washing & Rosenberg et al., 2006 \\
\hline $\begin{array}{l}\text { 6. Disconnect illegal connections }{ }^{c} \\
\text { 7. Ration service }\end{array}$ & 1.1 to 4.2 & 0.7 to 2.8 & -0.48 to -0.39 & per recent LEMA efforts & Griffin, 2004; LEMA, 2006 \\
\hline $\begin{array}{l}\text { - Current (Step 1) } \\
\text { - Drastic }(\text { Step 2) }\end{array}$ & $\begin{array}{l}12.0 \text { to } 20.0 \\
1000\end{array}$ & $\begin{array}{l}8.0 \text { to } 13.3 \\
1000\end{array}$ & $\begin{array}{c}0.00 \\
3.00 \text { to } 4.00\end{array}$ & $\begin{array}{l}\text { Existing rationing; untapped demand } \\
\text { unlimited; action of last resort; penalty }\end{array}$ & LEMA, 2006 \\
\hline
\end{tabular}
Notes:

a. Only lists actions with fixed upper limits

b. Upper limit can decrease if long-term conservation actions implemented

c. Upper limit scales with demand forecasts

Table 4. Shortage events with demand forecasts for year 2020

\begin{tabular}{llccc}
\hline \multicolumn{2}{c}{ Event Description } & Probability & \multicolumn{2}{c}{ Shortage level } \\
\cline { 5 - 5 } Demand Level & Available surface water & $(\%)$ & (Mm ${ }^{3} /$ year) & (\% of 2005 demand) \\
\hline 1. Small & Large & $4.1 \%$ & 47.0 to 75.0 & $35.3 \%$ to $56.3 \%$ \\
2. Below average & Above median & $11.4 \%$ & 75.0 to 105.0 & $56.3 \%$ to $78.8 \%$ \\
3. Slightly below average & Slightly above median & $27.8 \%$ & 105.0 to 132.5 & $78.8 \%$ to $99.5 \%$ \\
4. Slightly above average & Slightly below median & $33.8 \%$ & 132.5 to 157.5 & $99.5 \%$ to $118.2 \%$ \\
5. Above average & Below median & $20.1 \%$ & 157.5 to 182.5 & $118.2 \%$ to $137.0 \%$ \\
6. Large & Small & $1.7 \%$ & 182.5 to 192.2 & $137.0 \%$ to $144.3 \%$ \\
\hline
\end{tabular}




\section{Table 5. Optimized costs and implementation for long-term actions through 2020}

\begin{tabular}{|c|c|c|c|c|}
\hline \multirow[b]{2}{*}{ Long-Term Action } & \multicolumn{4}{|c|}{ Model Solution Approach } \\
\hline & $\begin{array}{c}\text { Determ.-Equiv. } \\
\text { (point values) }\end{array}$ & $\begin{array}{c}\text { Robust }^{\mathrm{a}} \\
\text { (data scenarios) }\end{array}$ & $\begin{array}{c}\text { Grey Number } \\
\text { (risk prone) }\end{array}$ & $\begin{array}{l}\text { Best / Worst } \\
\text { (case anal.) }\end{array}$ \\
\hline \multicolumn{5}{|l|}{ Supply Enhancement } \\
\hline 1. New surface water sources (desert check dams) & 5 & 5 & 5 & 5 \\
\hline 2. New local groundwater sources & 5 & 5 & 5 & 5 \\
\hline 3. New distant groundwater sources (Disi) & & & & $<0,1>$ \\
\hline \multicolumn{5}{|l|}{ 4. Sea-water desalination (Red-Dead Canal) } \\
\hline 5. Desalinate local brackish water (Zara-Ma'een) & & & & $<0,1>$ \\
\hline 6. Desalinate distant brackish waters & 9 & 10 & 6 & $<6,7>$ \\
\hline 7. Buy mobile desalination unit & 4 & 5 & & $<0,5>$ \\
\hline \multicolumn{5}{|l|}{ 8. Buy new water tanker truck } \\
\hline 9. Expand capacity to convey and treat water (Zai) & 1 & 1 & 1 & 1 \\
\hline \multicolumn{5}{|l|}{ 10. Expand capacity to recycle and reuse wastewater } \\
\hline \multicolumn{5}{|l|}{ Conservation } \\
\hline 11. Reduce physical losses (Capital Improvement Proj.) & 1 & 1 & & \\
\hline 12. Targeted customer water conservation program & 1 & 1 & 1 & $<1,0>$ \\
\hline \multicolumn{5}{|l|}{ 13. Rebates to customers who install } \\
\hline - Dual flush toilets & 1 & 1 & 1 & $<1,0>$ \\
\hline - Kitchen faucet aerators & 1 & 1 & 1 & $<1,0>$ \\
\hline - Drip irrigation & & & 1 & $<1,0>$ \\
\hline 14. Re-price water & 1 & 1 & 1 & 1 \\
\hline 15. Increase meter registration (retrofit rolled meters) & 1 & 1 & 1 & $<1,0>$ \\
\hline 16. Meter illegal connections & 1 & 1 & 1 & 1 \\
\hline \multicolumn{5}{|l|}{ Expected Annual Costs (JD Mill/year) } \\
\hline - For long-term actions & 34 & $(22,36,49)$ & {$[6,54]$} & $<6,78>$ \\
\hline - For short-term actions & -1 & $(-11,4,30)$ & {$[-21,226]$} & $<-21,34>$ \\
\hline - Total & 33 & $(19,40,66)$ & {$[-15,281]$} & $<-15,112>$ \\
\hline
\end{tabular}

a. Costs show lowest, average, and largest of 20 random, independently-sampled data scenarios

b. Grey-number approach only gives single, deterministic value for long-term decisions. Costs in brackets show stable, feasible range corresponding to solutions from lower- and upper-bound submodels.

c. Brackets show best followed by worst case values when the two values differ 


\section{Table 6. Implementation levels for short-term actions in shortage events $\left(\mathrm{Mm}^{3} /\right.$ year $)$}

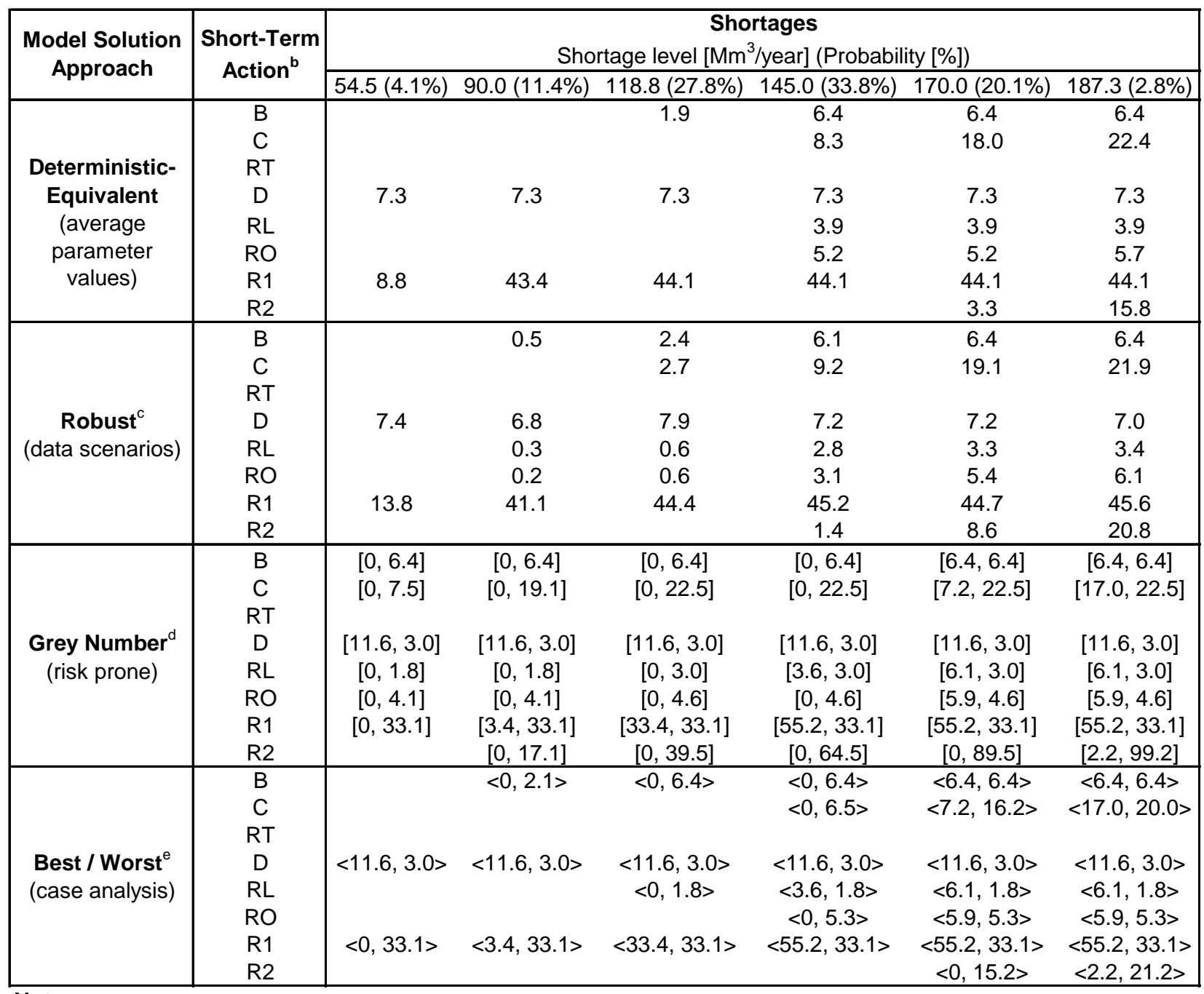

\section{Notes:}

a. Blank indicates zero value

b. $B=$ Buy ag. water, $C=$ Cloud seeding, RT = Rent tanker trucks, $D=$ Disconnect illegal connections, RL $=$ Reduce leak fix time, $\mathrm{RO}=$ Restrict outdoor water use, $\mathrm{R} 1=$ Normal rationing, $\mathrm{R} 2=$ Severe rationing

c. Average of 20 random, independently-sampled, data scenarios

d. Numbers in brackets show stable, feasible ranges spanning solutions to lower- and upper-bound submodels

e. Numbers in brackets show solutions for best and then worst cases 